\title{
Simulated Seasonal and Interannual Variability of the Mixed Layer Heat Budget in the Northern Indian Ocean*
}

\author{
Clément de Boyer Montégut ${ }^{+}$and Jérôme Vialard \\ Laboratoire d'Océanographie et du Climat, Expérimentations et Approches Numériques, Institut Pierre Simon Laplace, \\ Paris, France \\ S. S. C. SHENoI AND D. SHANKaR \\ Physical Oceanography Division, National Institute of Oceanography, Dona Paula, Goa, India \\ FABIEN DURAND \\ Laboratoire d'Etudes en Géophysique et Océanographie Spatiales, Institut de Recherche pour le Développement, \\ Toulouse, France \\ Christian Ethé and Gurvan Madec \\ Laboratoire d'Océanographie et du Climat, Expérimentations et Approches Numériques, Institut Pierre Simon Laplace, \\ Paris, France
}

(Manuscript received 3 May 2005, in final form 13 March 2006)

\begin{abstract}
A global ocean general circulation model (OGCM) is used to investigate the mixed layer heat budget of the northern Indian Ocean (NIO). The model is validated against observations and shows fairly good agreement with mixed layer depth data in the NIO. The NIO has been separated into three subbasins: the western Arabian Sea (AS), the eastern AS, and the Bay of Bengal (BoB). This study reveals strong differences between the western and eastern AS heat budget, while the latter basin has similarities with the BoB. Interesting new results on seasonal time scales are shown. The penetration of solar heat flux needs to be taken into account for two reasons. First, an average of $28 \mathrm{~W} \mathrm{~m}^{-2}$ is lost beneath the mixed layer over the year. Second, the penetration of solar heat flux tends to reduce the effect of solar heat flux on the SST seasonal cycle in the AS because the seasons of strongest flux are also seasons with a thin mixed layer. This enhances the control of SST seasonal variability by latent heat flux. The impact of salinity on SST variability is demonstrated. Salinity stratification plays a clear role in maintaining a high winter SST in the BoB and eastern AS while not in the western AS. The presence of freshwater near the surface allows heat storage below the surface layer that can later be recovered by entrainment warming during winter cooling (with a winter contribution of $+2.1^{\circ} \mathrm{C}$ in the $\mathrm{BoB}$ ). On an interannual time scale, the eastern $\mathrm{AS}$ and $\mathrm{BoB}$ are strongly controlled by the winds through the latent heat flux anomalies. In the western AS, vertical processes, as well as horizontal advection, contribute significantly to SST interannual variability, and the wind is not the only factor controlling the heat flux forcing.
\end{abstract}

* National Institute of Oceanography Contribution Number 4110.

+ Current affiliation: Frontier Research Center for Global Change, JAMSTEC, Yokohama, Japan.

Corresponding author address: Clément de Boyer Montégut, Frontier Research Center for Global Change, JAMSTEC, $3173-25$ Showa-machi Kanazawa-ku, Yokohama-city, Kanagawa 236-0001, Japan.

E-mail: clement@jamstec.go.jp

DOI: $10.1175 / J C L I 4148.1$

(C) 2007 American Meteorological Society 


\section{Introduction}

The northern Indian Ocean (NIO), forced by the seasonally reversing monsoon winds, exhibits the two characteristics of the monsoon. First, it has a highly repetitive seasonal cycle, which implies a strong climatology. The monsoon winds reverse twice a year, blowing generally from the southwest during summer (JuneSeptember) and from the northeast during winter (November-February) (see Fig. 1); March-May and October are the months of transition between the monsoons. Second, since no two monsoons are alike, in no two years does the NIO behave the same way: there is considerable interannual variability (Webster et al. 1998). This is reflected in the variations of temperature, salinity, and mixed layer processes and in the heat and salt budgets. The interannual variability of the heat budget of the upper ocean (or mixed layer) is of paramount interest for air-sea coupling.

Several studies have examined the seasonal cycle of the mixed layer in the Arabian Sea (AS) (Shetye 1986; Molinari et al. 1986; McCreary and Kundu 1989; McCreary et al. 1993) and the heat budget of the upper ocean using data (Düing and Leetmaa 1980; Rao et al. 1989; Rao and Sivakumar 2000; Shenoi et al. 2002, hereinafter SSS02) and numerical models (Fischer 2000; Prasad 2004). Shenoi et al. (2005b) examined the heat budget of the near-surface layers of the NIO using model output and found that the model reproduced the surface heat content correctly, except during the spring warming (March-April) when the surface heat content was overestimated. Using diversified datasets, Düing and Leetmaa (1980) and SSS02 identified two mechanisms responsible for the summer cooling of the AS: western boundary upwelling and the export of heat through meridional overturning across the southern boundary of the AS. Such summer cooling is absent in the Bay of Bengal (BoB) owing to weak upwelling and meridional overturning owing to weaker winds (Shenoi et al. 2005b).

The importance of salinity in the thermodynamics of the NIO, and its possible role in air-sea coupling, have aroused interest. Owing to the lack of salinity data on a scale comparable to temperature, especially sea surface temperature (SST), such studies have been restricted to the southeastern AS (Durand et al. 2004; Shenoi et al. 2004, 2005a; Shankar et al. 2004), the northern BoB (Vinayachandran et al. 2002), and a few other regions (Rao et al. 1985). These studies have highlighted the importance of upper-ocean stratification, caused by the freshwater fluxes, for the thermodynamics of the upper ocean. The stratification due to salinity leads to the

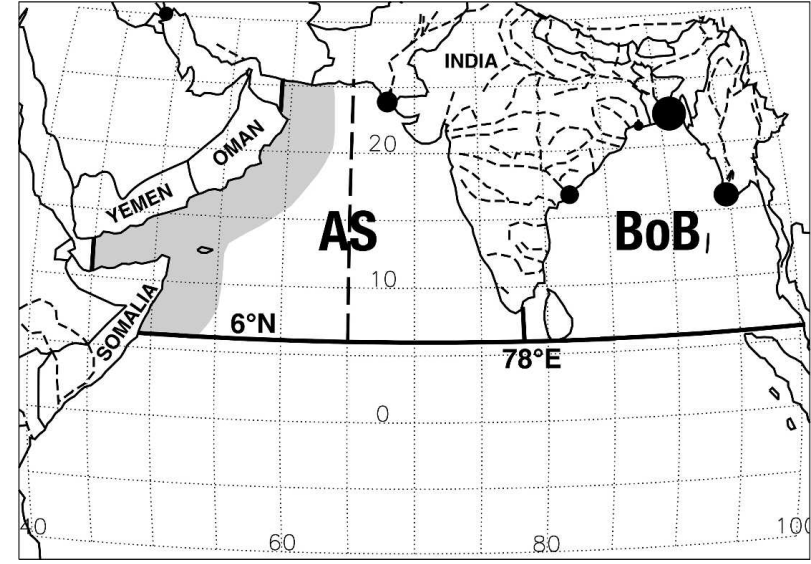

FIG. 1. Map of the northern Indian Ocean along with the main rivers of the region. River runoff parameterized in the model is shown with dots whose size increases with increasing mean annual discharge of the river. The NIO is divided by the Indian subcontinent into two semienclosed basins: the Arabian Sea (AS) and the Bay of Bengal (BoB). The dashed meridional line at $65^{\circ} \mathrm{E}$ separates the western and eastern AS. The gray area corresponds to the western AS coastal zone (to $\sim 350 \mathrm{~km}$ from the coast). The $6^{\circ} \mathrm{N}$ parallel indicates the southern limit of the basins considered in this study.

existence of a barrier layer similar to that in the western tropical Pacific (see, e.g., Vialard and Delecluse 1998). Sengupta et al. (2002) highlighted the importance of penetrative solar radiation in determining the upperlayer heat budget of the eastern AS. Both the barrier layer, which often leads to subsurface inversions (Shankar et al. 2004; Durand et al. 2004), and the resulting penetrative solar radiation play a crucial role in these regions.

The above studies were successful in describing the seasonal cycles, but the natural extension to interannual variability has not been made owing to the paucity of salinity data. It is this lacuna that numerical models can fill. Murtugudde and Busalacchi (1999, hereinafter MB99) used an ocean general circulation model (OGCM) to show that the interannual variability of SST in the AS and in the Somali Current depends not only on variability in air-sea fluxes, but also on the wind forcing: in other words, oceanic processes play an important role in regulating SST. Vinayachandran (2004) used data from Argo floats to show that the length of the summer monsoon plays a key role in the summer cooling. None of the studies on interannual variability, however, are as comprehensive as those (cited above) on the seasonal cycle.

Hence, in this paper, we use an OGCM to investigate the interannual variability in the heat budget of the upper layers of the NIO. In doing so, we also include 
(a) MLD from the model $(\mathrm{m})$
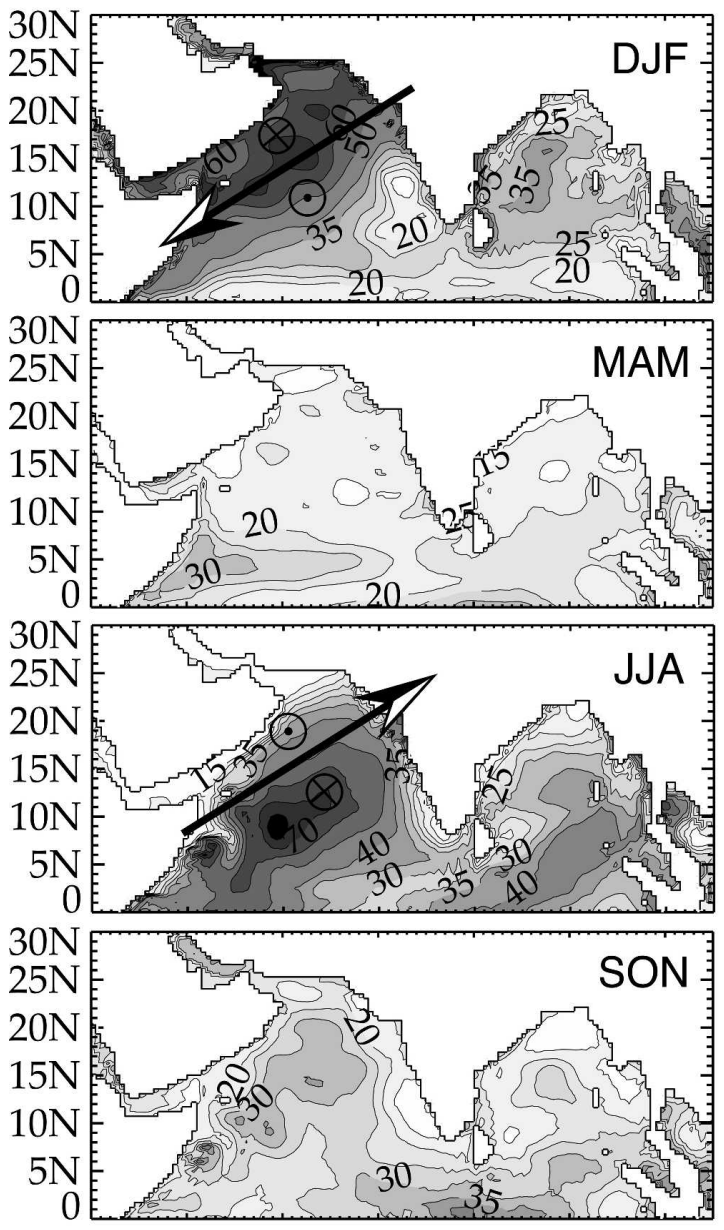

40E 50E 60E 70E $80 \mathrm{E}$ 90E 100E (b) MLD from observations ( $\mathrm{m}$ )
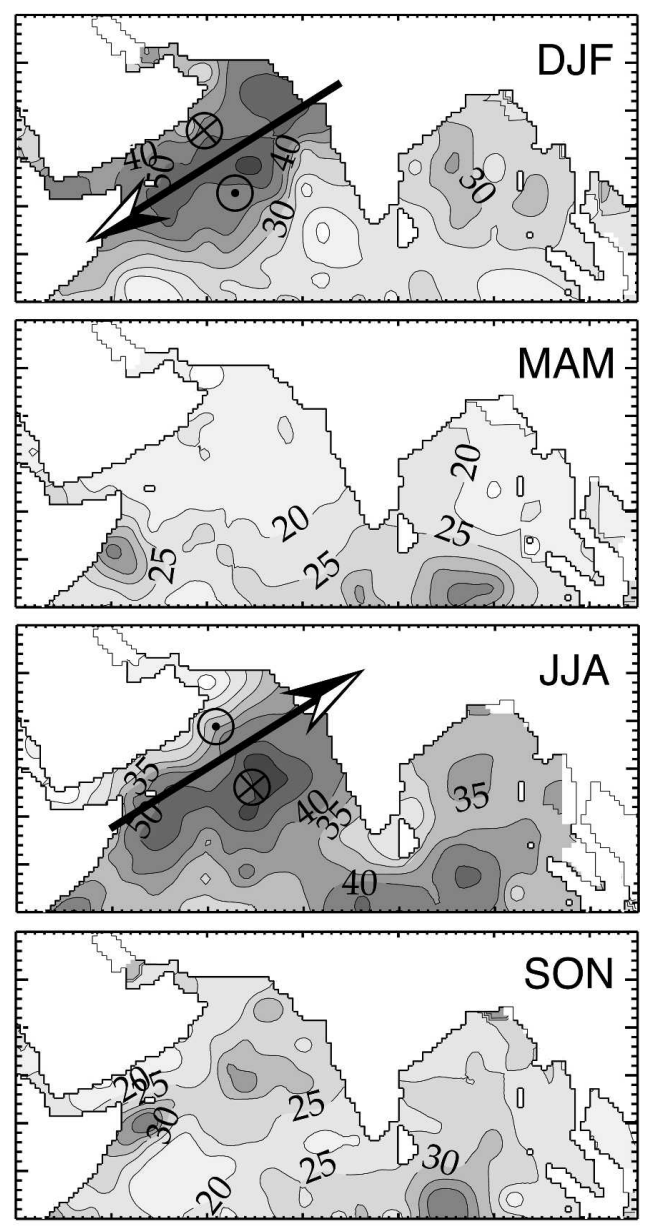

FIG. 2. Seasonal maps of MLD for DJF, MAM, JJA, and SON for (a) the model MLD, defined as the depth at which density is $0.01 \mathrm{~kg} \mathrm{~m}^{-3}$ greater than the sea surface density, and (b) the MLD from de Boyer Montégut et al. (2004), defined with a $\Delta \sigma_{\theta}=0.03 \mathrm{~kg} \mathrm{~m}^{-3}$ from the density at $10-\mathrm{m}$ depth. Further comments are given in the text about the criterion difference between data and model. The seasonal climatology for the model is computed over 1993-2000. The black arrows in the DJF and JJA panels indicate the climatological axes of the winds, especially the Findlater (1969) jet in JJA. Symbols also denotes positive $(\odot)$ or negative $(\otimes)$ Ekman pumping on each side of the wind axes. Contour interval is $5 \mathrm{~m}$ from 10 to $40 \mathrm{~m}$ and $10 \mathrm{~m}$ from $40 \mathrm{~m}$ to higher values.

the effects of the barrier layer and penetrative radiation. This investigation has several advantages over the previous studies mentioned above. The heat budgets of Düing and Leetmaa (1980) and Shenoi et al. (2002, $2005 \mathrm{~b}$ ) estimated the budgets for fixed control volumes (50 $\mathrm{m}$ thick in the latter). Here, we estimate the heat budget of the mixed layer rather than the budget over a fixed layer because the mixed layer in the NIO (Fig. 2) is often thinner than $50 \mathrm{~m}$, implying that using a fixed control volume allows processes below the mixed layer to influence the SST. Following the suggestion of SSS02, we also estimate separately the heat budgets for the western and eastern $\mathrm{AS}$; the $65^{\circ} \mathrm{E}$ meridian separates these two parts of the basin. The southern boundary of the regions of study, shown in Fig. 1 , is at $6^{\circ} \mathrm{N}$. The heat budgets are computed online in the model using a time-varying mixed layer depth (MLD). The model computes air-sea fluxes internally, enabling a closed budget.

We begin by describing the model and the method used to estimate the budgets (section 2); then we investigate the seasonal cycle (section 3 ) and the interannual variability during 1993-2000 (section 4). Section 5 summarizes the paper. 


\section{Model and data}

\section{a. Physics of the model}

The OGCM used in this study is the Océan Parallélisé (OPA) model (Madec et al. 1999; see the full documentation online at http://www.lodyc.jussieu.fr/ opa/), developed at the Laboratoire d'Océanographie et du Climat, Expérimentation et Approches Numériques (LOCEAN). OPA solves the primitive equations on an Arakawa $\mathrm{C}$ grid, with a second-order finite difference scheme. It assumes the Boussinesq and hydrostatic approximations, the incompressibility hypothesis, and uses a free-surface formulation (Roullet and Madec 2000). The density is computed from potential temperature, salinity, and pressure using the Jacket and McDougall (1995) equation of state. In its global configuration ORCA05, the horizontal mesh is based on a $0.5^{\circ} \times 0.5^{\circ}$ Mercator grid, and following Murray (1996) two numerical inland poles have been introduced in order to remove the North Pole singularity from the computational domain. The departure from the Mercator grid starts at $20^{\circ} \mathrm{N}$ and is constructed using a series of embedded ellipses based on the semianalytical method of Madec and Imbard (1996). Realistic bottom topography and coastlines are derived from the study of Smith and Sandwell (1997), complemented by the $5^{\prime}$ Gridded Earth Topography (ETOPO5) dataset. The maximum depth of $5000 \mathrm{~m}$ is spanned by $30 \mathrm{z}$ levels ranging from $10 \mathrm{~m}$ in thickness in the upper $120 \mathrm{~m}$ to $500 \mathrm{~m}$ at the bottom. The ocean model is run with a time step of $2400 \mathrm{~s}$.

Lateral tracer mixing is done along isopycnals. Eddyinduced tracer advection is parameterized following Gent and McWilliams (1990) with coefficients decreased in the Tropics between $20^{\circ} \mathrm{N}$ and $20^{\circ} \mathrm{S}$. Momentum is mixed along horizontal surfaces using coefficients varying with latitude, longitude, and depth. Vertical eddy diffusivity and viscosity coefficients are computed from a 1.5-level turbulent closure scheme based on a prognostic equation for the turbulent kinetic energy (Blanke and Delecluse 1993). Double diffusive mixing (i.e., salt fingering and diffusive layering) is computed following Merryfield et al. (1999). Penetrative solar radiation corresponding to Type I water (Jerlov 1968) is also used. The suitability of such a water type in the NIO will be discussed later in the paper.

\section{b. Initialization and surface fluxes}

The model run starts from an ocean at rest using the January temperature and salinity fields of the Levitus (1998) climatology. It is spun up for a 3-yr period using a climatology of 1992-2000 forcing fields before starting the interannual simulation from 1992 to 2000 . In the rest of the paper, we will study the 1993-2000 period.

The momentum surface boundary condition is given using the weekly European Remote Sensing Satellites-1 and -2 (ERS-1-2) wind stress interpolated daily with a cubic spline method. The insolation, longwave radiation and turbulent heat fluxes (and the evaporation) are computed from the semiempirical or bulk formulae (Timmermann et al. 2005), which relate the fluxes to the SST (computed by the model) and to meteorological parameters (10-m wind speed, surface air temperature and relative humidity, cloudiness). The daily wind speed is given by interpolation of $E R S-1-2$ weekly wind speed. The daily $2-\mathrm{m}$ air temperature is extracted from the National Centers for Environmental PredictionNational Center for Atmospheric Research (NCEPNCAR) reanalysis (Kalnay et al. 1996). Monthly climatologies of relative humidity (Trenberth et al. 1989) and cloudiness (Berliand and Strokina 1980) are used. We will discuss later in the paper the limitations inherent in using climatological values for relative humidity and cloudiness.

Freshwater fluxes from rain and river runoffs are important in maintaining the sea surface salinity (SSS) structure in the NIO, where important salinity gradients exist. Precipitation data come from the Climate Prediction Center Merged Analysis of Precipitation (CMAP) product (Xie and Arkin 1996). This product has been shown to produce better surface salinity fields than others for the Indian Ocean (Yu and McCreary 2004). Major river runoffs are also taken into account in our experiments, as they can have strong impacts on the Bay of Bengal upper structure (Han et al. 2001). The monthly values of river discharge (UNESCO 1996) are introduced into the model by distributing the associated freshwater input as a precipitation on the points surrounding the mouth of the rivers. Figure 1 shows the location of the main river runoffs in the model.

A restoring term toward the Levitus (1998) SSS is applied to the freshwater budget, with a relaxation time scale of 2 months for a 50-m-thick layer. While there is no physical justification for this feedback term, as the atmosphere does not care about ocean surface salinity, it avoids SSS drift arising from the error in the prescribed freshwater budget. Simulating a proper SSS is, indeed, essential as it can have strong influences on the thermodynamic structure of the mixed layer (e.g., Vialard and Delecluse 1998; Durand et al. 2004).

\section{c. Mixed layer heat or salinity budget in the model}

One of the main goals of this work is to understand how oceanic processes act to balance the atmospheric forcing and regulate the SST in the NIO. To do so, a 
mixed layer budget method (Vialard and Delecluse 1998; Vialard et al. 2001) allows us to compute the vertically averaged temperature (salinity) tendency terms within the time-varying MLD. The depth of the mixed layer over which the diagnostic is applied, is computed using a density criterion. This depth is the bottom of the last model level from the surface, where the density is smaller than the sea surface density plus $0.01 \mathrm{~kg} \mathrm{~m}^{-3}$. Such a small criterion allows the vertically averaged mixed layer temperature $T_{\mathrm{ml}}$ to be a quite good proxy of the SST. Therefore, the final equation for $T_{\mathrm{ml}}$ reads

$$
\begin{aligned}
& \partial_{t} T_{\mathrm{ml}}=\underbrace{\frac{1}{h} \int_{-h}^{0} u \partial_{x} T d z-\frac{1}{h} \int_{-h}^{0} v \partial_{y} T d z}_{\text {horizontal advection }} \underbrace{-\frac{1}{h} \int_{-h}^{0} D_{l}(T)}_{\text {lateral processes }} \\
& \underbrace{-\frac{1}{h}\left(T_{\mathrm{ml}}-T_{-h}\right)\left(w_{-h}+\partial_{t} h\right)-\frac{1}{h}\left[K_{z} \partial_{z} T\right]_{-h}}+\underbrace{\frac{Q_{s}\left(1-\mathcal{F}_{-h}\right)+Q_{n s}}{\rho_{0} C_{p} h}}, \\
& \text { subsurface vertical processes }(\simeq \text { vertical mixing) } \\
& \text { atmospheric forcing }\left(F_{T}\right)
\end{aligned}
$$

where $h$ is the time-varying depth of the model mixed layer; $(u, v, w)$ are the components of ocean currents; $D_{l}(\cdot)$ is the model lateral mixing operator (eddyinduced tracer advection will be grouped in the lateral processes term as a parameterization of the subgridscale lateral mixing); $T_{-h}$ is the temperature at the base of the mixed layer; $K_{z}$ is the vertical mixing coefficient for tracers; $Q_{n s}$ and $Q_{s}$ are, respectively, the nonsolar and solar components of the total heat flux; $\mathcal{F}_{-h}$ is the fraction of solar shortwave radiation that penetrates through the base of the mixed layer; $\rho_{0}$ is the seawater reference density; and $C_{p}$ is the seawater heat capacity. This equation clearly shows the importance of the MLD in the tendency balance (1) and hence in the diagnostic of the mixed layer temperature. We have the same equation for the salinity budget by replacing temperature $T$ and $T_{\mathrm{ml}}$, respectively, with salinity $S$ and $S_{\mathrm{ml}}$, and taking as the forcing term the following expression: $F_{S}=h^{-1}$ SSS $(E-P-R)$, with SSS the sea surface salinity, and $E, P, R$, respectively, the evaporation and precipitation fluxes and the river runoff.

In Eq. (1), the subsurface vertical processes term represents the heating rate due to all oceanic vertical processes occurring at the base of the mixed layer. These are vertical advection: $-h^{-1} w_{-h}\left(T_{\mathrm{ml}}-T_{-h}\right)$, entrainment mixing: $-h^{-1} \partial_{t} h\left(T_{\mathrm{ml}}-T_{-h}\right)$, and vertical turbulent mixing: $-h^{-1}\left[K_{z} \partial_{z} T\right]_{-h}$. Following Vialard et al. (2001), those terms have been grouped together due to the Lagrangian nature of our diagnostics.

It is also important to note that the horizontal advection (and lateral processes) term not only represents an exchange within the mixed layer, but it also represents an exchange between the mixed layer and the interior ocean in regions of high mixed layer depth gradient.
Therefore, in integrated budgets over the AS or the $\mathrm{BB}$, the horizontal advection term is not only what enters/exits at the boundary of the domain but also what enters/exits at the mixed layer bottom.

\section{Seasonal variability}

\section{a. Validation of the model}

The time-varying depth of the mixed layer is a crucial parameter for the mixed layer heat budget and hence the SST (e.g., Chen et al. 1994; Qiu et al. 2004). Modeling properly the mixed layer physics and diagnosing a correct MLD is the first necessary step to assess the surface temperature or salinity budgets.

The model MLD has been compared to a gridded MLD product, resulting from interpolation of the MLD estimated from more than 4 million individual profiles and gridded onto a $2^{\circ}$ resolution grid (de Boyer Montégut et al. 2004). This product has recently been upgraded to include Argo floats, which considerably improves the coverage in the Indian Ocean, and to include estimates of the barrier-layer thickness (de Boyer Montégut et al. 2007; Mignot et al. 2007). Figure 2 shows the seasonal MLDs from the model and from observations. The method to compute the MLD is the same for both sources, being based on the average of MLDs from instantaneous profiles. The model online heat budget computations were performed with a 0.01 $\mathrm{kg} \mathrm{m}^{-3}$ criterion for the MLD. Because of the diurnal variability, a higher criterion $\left(0.03 \mathrm{~kg} \mathrm{~m}^{-3}\right)$ has to be applied in the data (de Boyer Montégut et al. 2004). Nevertheless, it has been confirmed that the MLD obtained from the model with both criteria is almost iden- 
tical ( $\sim 5 \mathrm{~m}$ maximum difference for the annual mean state over most of the region, not shown).

Seasonal MLDs from the model are in good agreement with observations, and the main features are well reproduced. For example, the AS exhibits a MLD with a large semiannual cycle, which is characteristic of that region in both data and model. It is a consequence of the annual cycle in the surface forcing due to seasonally reversing monsoon winds (Schott and McCreary 2001).

The summer and winter monsoon MLDs in the Arabian Sea are on average about $10 \mathrm{~m}$ deeper in the model than in the observations. However, these differences are regionally dependent. The model is systematically deeper than observations in regions of negative Ekman pumping. For example, during the summer monsoon, a deep bias is found in the model southeast of the Findlater (1969) jet axis (Fig. 2). The model therefore seems to enhance the effect of negative Ekman pumping on MLD deepening. Previous studies actually showed that Ekman pumping does not dominate the upper-ocean response in the AS but rather acts as a modulation of wind-driven entrainment in summer and convective overturning in winter (e.g., Lee et al. 2000; Fischer et al. 2002). In addition, McCreary et al. (2001) also noted the same deep bias for their model in winter in the AS and suggested that it could result from deficiencies in the parameterization of their mixed layer physics based on a diagnostic production of turbulent kinetic energy.

In summer and fall, shallow MLDs are found in the model along the coast of India. This shallow MLD in the model is fairly realistic and is likely linked to the advection of the low salinity water along the coast by the East India Coastal Current after the summer monsoon runoff in the north of the $\mathrm{BoB}$ (Eigenheer and Quadfasel 2000). This feature is not found in the observed MLD but might be due to poor observational coverage close to the coast of India. The MLD climatology based on temperature-only data has much better coverage. It does present shallow MLDs along the coast (de Boyer Montégut et al. 2004) and the model MLD is indeed in good agreement with the climatology in that area.

A region of particular interest is the southeastern Arabian Sea. Recent papers have shown that a thin mixed layer (less than $20 \mathrm{~m}$ ) and a thick barrier layer occurring in winter have the potential to impact the SST maximum and onset of the summer monsoon (e.g., Durand et al. 2004; Masson et al. 2005). Such a feature is present in both data and model, and the barrier layer thickness is also in good agreement between the data and model with maximum values over $20 \mathrm{~m}$ in February (not shown).
Other validations (not shown) to the observed seasonal cycle of SST (Reynolds and Smith 1994), gridded sea level [produced by Collecte Localisation Satellites (CLS) and available online at http://www.jason. oceanobs.com/], and sea surface salinity (Levitus 1998) were performed. The SST seasonal cycle is very well reproduced (with correlations above 0.8 almost everywhere). The sea level seasonal cycle is in good agreement in regions where it is dominated by the large-scale circulation and slightly underestimated in regions of strong eddy activity. The large-scale surface current seasonal cycle is in good agreement with the description by Schott and McCreary (2001). The overall seasonal upper-ocean variability in the NIO is hence reasonably reproduced by the model. We can thus use the model to investigate the seasonal heat budget in the NIO.

\section{b. The mixed layer heat budget}

In this section, the model is used to evaluate the seasonal heat budget of the mixed layer in the NIO. The previous most comprehensive study of this type, using observations, was the one from SSS02. In addition to using a model, the present study has a few differences from SSS02. First, we integrate the heat budget over a time-varying mixed layer, rather than a fixed 50-m layer. Second, as suggested by SSS02 we chose to present separately the budget for the eastern and western AS, delimited by $65^{\circ} \mathrm{N}$ to illustrate the different behavior of the western AS (where upwelling processes play an important role) and the eastern AS. Third, we take the solar energy penetration into account in this study: with the shallow mixed layer that sometimes occurs in this region, this can indeed result in a significant part of the incoming solar heat flux penetrating below the mixed layer and heating deeper layers. In the overview below, we will brush up on the main features of the three subbasins and emphasize the new results in this study, compared to SSS02 or MB99. We will then describe the seasonal heat budget in the three subbasins in more detail.

\section{1) OVERVIEw}

The mean temperature over $0-50 \mathrm{~m}\left(T_{50}\right)$ is indicated in Fig. 3 since SSS02 computed the heat budget over this fixed layer. It can be seen that there are important differences that appear seasonally between the $T_{50}$ and mixed layer temperature. For example, a difference of more than $1^{\circ} \mathrm{C}$ can be observed in the western AS in May when the mixed layer is shallowest. This shows that a precise quantification of the processes that affect SST requires an integration over the time-varying mixed layer depth. SST is not shown in Fig. 3 as it is 
(a) Western Arabian Sea
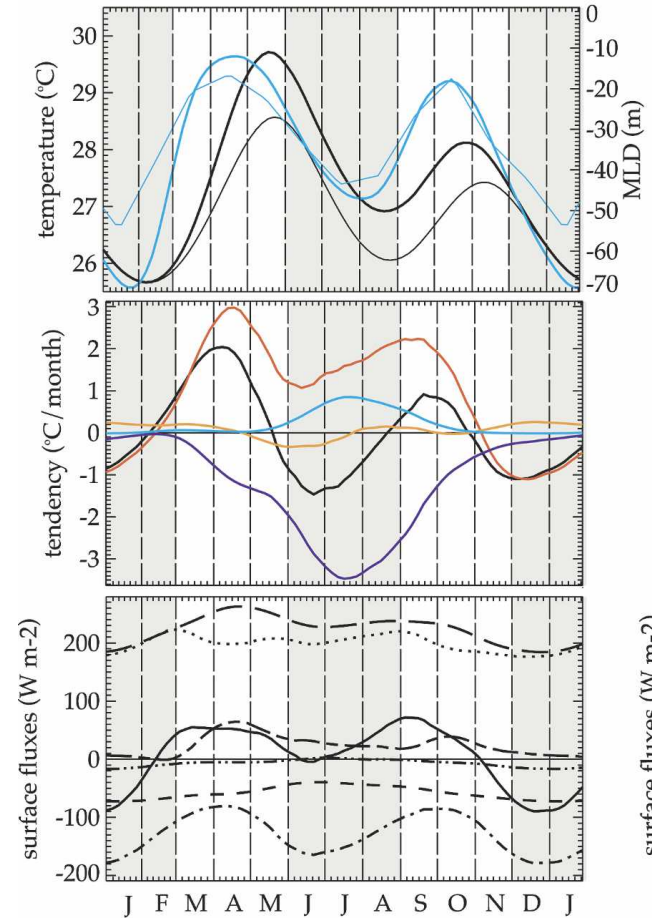

(c) Bay of Bengal
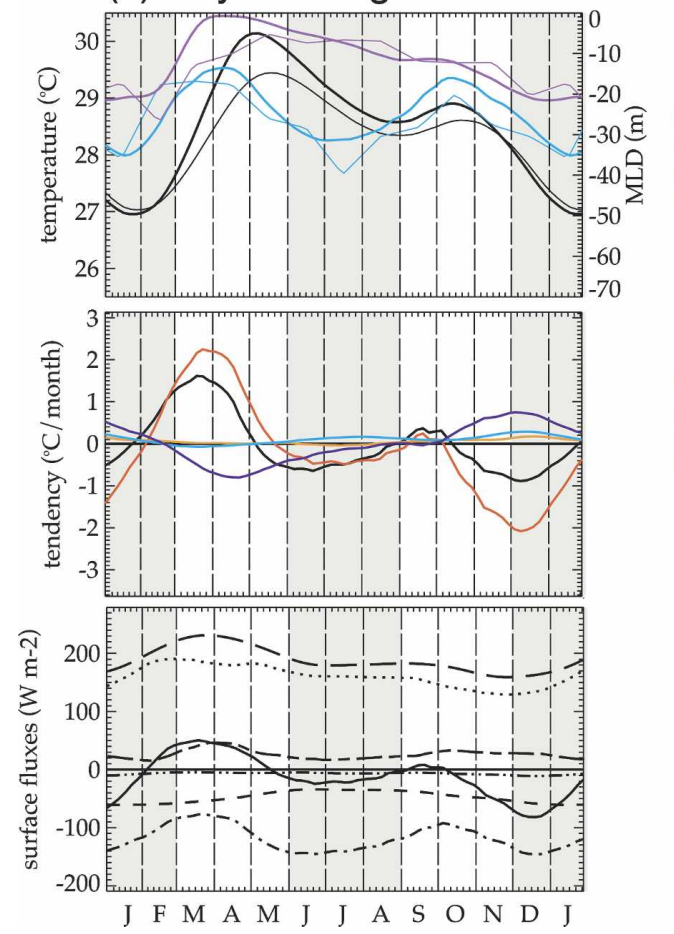

FIG. 3. (top) Mixed layer depth, mixed layer temperature ( $T_{\mathrm{ml}}$, a proxy for SST), temperature integrated over 0-50 m ( $\left.T_{50}\right)$, and barrier layer thickness (BLT) computed following de Boyer Montégut et al. (2004); (middle) SST seasonal tendencies in the mixed layer; and (bottom) surface heat fluxes (positive into the ocean), effective net heat flux in the mixed layer $\left(Q_{\text {eff }}=Q_{\text {net }}-Q_{\text {pen }}\right)$, net shortwave radiation flux in the mixed layer $\left[Q_{\mathrm{sw}}(\mathrm{ml})\right]$, net shortwave radiation flux at the surface $\left(Q_{\mathrm{sw}}\right)$, latent heat flux $\left(Q_{\text {lat }}\right)$, net longwave radiation flux $\left(Q_{\text {lw }}\right)$, sensible heat flux $\left(Q_{\text {sens }}\right)$, and penetrative solar heat flux $\left[Q_{\text {pen }}=Q_{\text {sw }}-Q_{\text {sw }}(\mathrm{ml})\right]$, in (a) the western AS, (b) eastern AS, and (c) BoB.
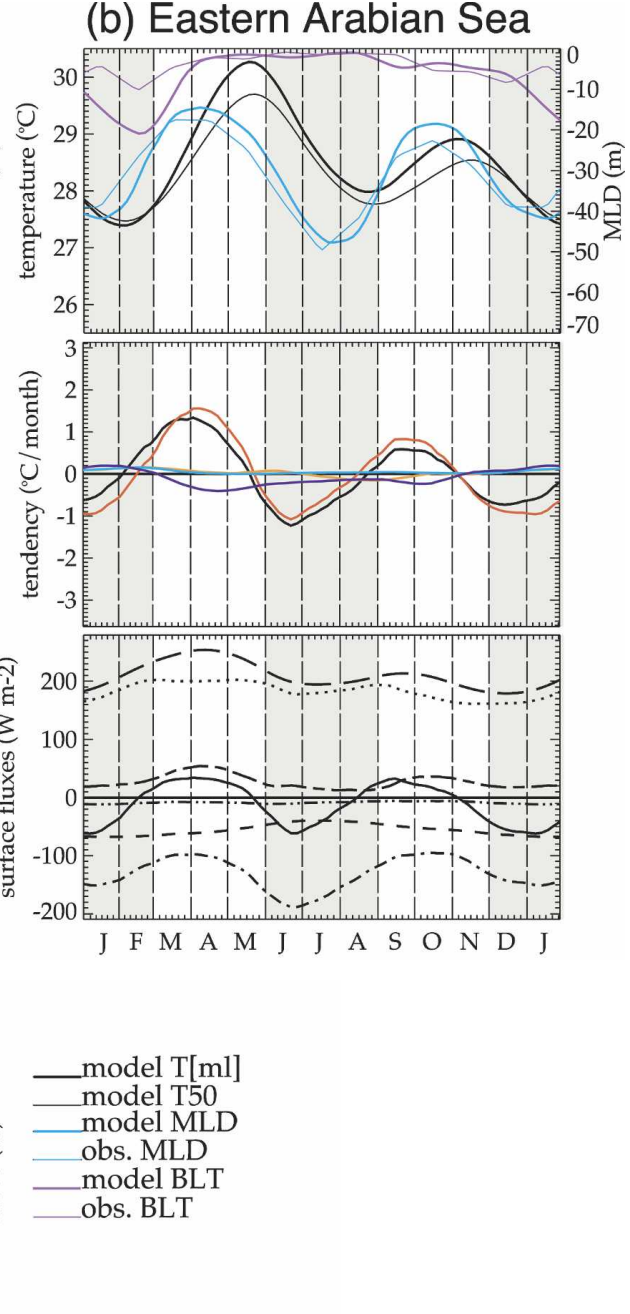

total tendency atmospheric forcing lateral processes

vertical processes

horiz. advection

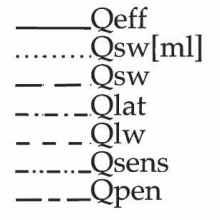


TABLE 1. Annual heat fluxes for the three regions of interest: $Q_{\text {net }}$ is the net downward heat flux at the surface, $Q_{\text {pen }}$ is the penetrative solar heat flux, and $Q_{\text {eff }}$ is the effective heat flux available to warm the mixed layer $\left(Q_{\text {eff }}=Q_{\text {net }}-Q_{\text {pen }}\right)$. The standard deviation of the solar heat flux $\left(Q_{\mathrm{sw}}\right)$ and of the solar heat flux into the mixed layer $\left[Q_{\text {sw }}(\mathrm{ml})\right]$ are also shown. Fluxes are in $\mathrm{W} \mathrm{m}{ }^{-2}$.

\begin{tabular}{lccccc}
\hline \hline \multicolumn{1}{c}{ Region } & $Q_{\text {net }}$ & $Q_{\text {pen }}$ & \multicolumn{1}{c}{$Q_{\text {eff }}$} & $\begin{array}{c}Q_{\text {sw }} \\
\text { std dev }\end{array}$ & $\begin{array}{c}Q_{\text {sw }}(\mathrm{ml}) \\
\text { std dev }\end{array}$ \\
\hline Western Arabian Sea & 35.7 & 25.2 & 10.5 & 23.0 & 13.7 \\
Eastern Arabian Sea & 17.8 & 26.9 & -9.1 & 22.7 & 14.4 \\
Bay of Bengal & 17.9 & 28.3 & -10.4 & 22.0 & 19.0 \\
\hline
\end{tabular}

very similar to the mixed layer temperature, which means that the latter is a quite good proxy of SST.

The observed and modeled MLDs are plotted in Fig. 3 as the MLD is an essential parameter in these budgets. The basin-scale agreement is fairly good except during the winter monsoon in the western AS. The same comparison between the data and model is done for the barrier-layer thickness. No barrier layer occurs in the western AS. In the eastern AS and in the BoB, the barrier-layer thickness is maximum in winter in both data and model.

The surface heat fluxes have globally the same behavior in the three basins (Fig. 3). The semiannual cycle of the net heat flux is essentially driven by latent heat flux variations with the solar heat flux playing a secondary role. Longwave radiation is not negligible, ranging between 30 and $80 \mathrm{~W} \mathrm{~m}^{-2}$, but has small variability, while the sensible heat flux is nearly nil at any time. Table 1 shows the annual net heat flux for the three subbasins. It is an annual net heat gain of $28.3 \mathrm{~W} \mathrm{~m}^{-2}$ for the AS, in good agreement with the $24 \mathrm{~W} \mathrm{~m}^{-2}$ of Düing and Leetmaa (1980). However, when comparing our fluxes with the recent Southampton Oceanographic Center (SOC) climatology (see SSS02, their Fig. 8), one realizes that we have a weaker shortwave gain in all basins and a stronger latent heat loss in the AS during monsoons. This is also the case for older climatologies and for the NCEP or European Centre for MediumRange Weather Forecasts (ECMWF) heat fluxes (Weller et al. 1998). These fluxes differences are addressed further in section 5 .

Taking the penetrative solar heat flux ( $Q_{\text {pen }}$ in Fig. 3) into account is important, especially in regions with a thin mixed layer (Lewis et al. 1990; Anderson et al. 1996). This is the case in the western Arabian Sea where up to $65 \mathrm{~W} \mathrm{~m}^{-2}$ can be lost beneath the mixed layer in April when it reaches a minimum of $15 \mathrm{~m}$. This represents roughly half of the net heat flux into the ocean and neglecting $Q_{\text {pen }}$ would increase the predicted SST by $3.5^{\circ} \mathrm{C}$ over the month of April. Table 1 shows
TABLE 2. Influence of salinity stratification on the mixed layer heat budget through the barrier layer warming effect during the winter monsoon cooling phase in the three regions of interest. Temperatures are in ${ }^{\circ} \mathrm{C}$.

\begin{tabular}{lcccc}
\hline \hline \multicolumn{1}{c}{ Region } & $T_{\text {fall }}$ & $T_{\text {winter }}$ & $\Delta T$ & $\begin{array}{c}\text { Barrier } \\
\text { layer warming }\end{array}$ \\
\hline West Arabian Sea & 28.2 & 25.7 & -2.5 & 0.0 \\
East Arabian Sea & 28.9 & 27.4 & -1.5 & 0.4 \\
Bay of Bengal & 28.9 & 27.0 & -1.9 & 2.1 \\
\hline
\end{tabular}

the effective net heat flux into the surface mixed layer $\left(Q_{\text {eff }}\right)$. In our case, it turns the annual net heat gain at the surface into an annual net heat loss for the mixed layer in the eastern AS and the BoB. The penetration of solar heat flux also contributes to significantly damping the solar heat flux variability in the mixed layer (Table 1). Intermonsoon seasons indeed correspond to maximum net surface heat flux and minimum mixed layer depth, which results in a compensating effect for the net heat flux received by the mixed layer. In the AS, this reduces the variability of the solar heat flux by roughly $40 \%$. In the BoB, where the MLD is very shallow, reaching maxima of only $35 \mathrm{~m}$, heat loss under the mixed layer occurs all year long (Fig. 3c).

The influence of salinity on the mixed layer heat budget appears to be an important factor in understanding why the winter SST decrease is more important in the western than in the eastern AS (Fig. 3). Both subbasins experiences an atmospheric heat loss of $2.3^{\circ} \mathrm{C}$ during winter (November-January). However, heat accumulated in the barrier layer in the eastern AS warms the surface layer by $0.4^{\circ} \mathrm{C}$ (Table 2). Meanwhile, no barrier layer develops in the western AS and vertical mixing cools the mixed layer by $-0.8^{\circ} \mathrm{C}$. This can contribute to the winter SST difference between the two subbasins. As will be seen in the following subsection, the BoB also experiences a moderate heat loss during winter in spite of high atmospheric heat loss. This is due to the warming effect of the heat accumulated in the barrier layer in the previous seasons. Now that we have commented on the common features of the three basins and emphasized some new results, let us investigate in more detail the particularities of each basin. As processes are most often linked together, we will now stick to a description of the heat budget season by season.

\section{2) Western Arabian Sea}

The western AS SST experiences two seasons of warming during intermonsoon phases (March-May and September-October) and two seasons of cooling during both monsoons (June-August and NovemberFebruary). During the intermonsoon, atmospheric forc- 
(a) Western Arabian Sea coastal zone

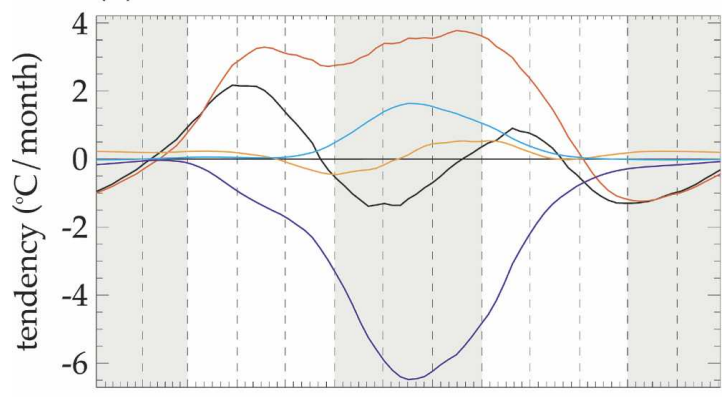

(b) Central Western Arabian Sea

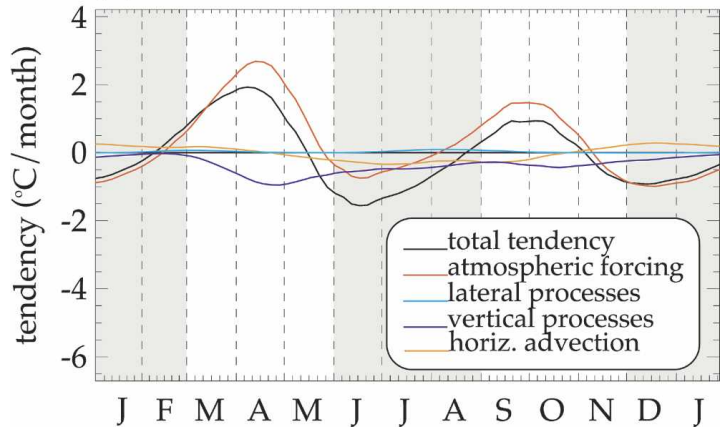

FIG. 4. SST seasonal tendencies in the mixed layer for (a) the western AS coastal zone (gray area in Fig. 1) and (b) the remaining western AS (central western AS). Note that the range in tendency is greater than the one used in Fig. 3.

ing and subsurface vertical processes are the driving mechanisms of the SST variability. In winter, the evolution of SST is driven by atmospheric forcing alone. On the other hand, in summer all oceanic processes act to balance the SST tendency (Fig. 3a, middle panel). The summer heat budget in this region is strongly dominated by the upwellings along Somali and Omani coasts as will be seen later in this section. During this season, one can notice that the two curves corresponding to atmospheric forcing $\left[F_{T}\right.$ in Eq. (1)] and to $Q_{\text {eff }}$, respectively, can be quite different (Fig. 3a). This is due to the nonlinearity of the spatial averaging over the basin: $\overline{Q_{\text {eff }}}=\overline{\rho_{0} C_{p} F_{T} h}=\rho_{0} C_{p}\left(\overline{F_{T}} \bar{h}+\overline{F_{T}{ }^{\prime} h^{\prime}}\right)$. In addition, during summer $F_{T}$ and $h$ are strongly correlated spatially so that the nonlinear term is not negligible ( $h$ is small and $F_{T}$ is high in the coastal zone, vice versa elsewhere). We will therefore make a separate heat budget for coastal and noncoastal zones to show the differences between those two regions during summer (Fig. 4).

Spring is the first warming phase, with the atmospheric forcing tendency increasing to its maximum in April. Very low winds result in reduced heat losses. This is combined with a very shallow mixed layer $(\simeq 15 \mathrm{~m})$, which is also an essential factor for increasing the atmospheric heating rate. SST becomes homoge- neous and very high over all of the AS. Consequently, the vertical temperature gradient with subsurface temperature increases and the subsurface cooling effect is more marked. The beginning of upwelling in May also increases the subsurface vertical process cooling. Solar heat flux is maximum due to clear-sky conditions and penetrative solar radiation is also maximum during this period due to the thin mixed layer $\left(\simeq 50 \mathrm{~W} \mathrm{~m}^{-2}\right)$. This contributes to a reduction in the surface layer heating and to enhanced heating of the subsurface water underneath the mixed layer.

With the summer monsoon onset, oceanic processes become a strong contributor to the heat budget, counterbalancing the heat accumulated in the previous months near the surface. As shown in previous studies (e.g., McCreary and Kundu 1989; SSS02), cooling by subsurface vertical processes is very important in the western AS in summer. During that season, the mixed layer heat budget can be separated between the coastal zone (about $350 \mathrm{~km}$ wide, Fig. 1) and the central western AS (Fig. 4). Western AS heat budget features observed in Fig. 3a (middle panel) are therefore mainly dominated by strong oceanic processes occurring in the coastal upwelling areas (Fig. 4a). On the other hand, the central western AS closely resembles the eastern AS, without any influence of the barrier-layer warming in winter (Fig. 4b). In the upwelling regions, vertical advection maintains a shallow MLD (Fig. 2a) and also enhances the stratification below the mixed layer. The $20^{\circ} \mathrm{C}$ isotherm lies at $40 \mathrm{~m}$ near the Omani coast while reaching $160 \mathrm{~m}$ in the center of the basin (not shown). Vertical mixing between the mixed layer and the cold upwelled water that lies below creates the greatest part of the cooling in the western AS coastal zone (Fig. 4a). In the central western AS, both vertical processes and horizontal advection contribute to cooling the SST (Fig. $4 \mathrm{~b})$. Following the eastward summer monsoon current across the Arabian Sea (Shankar et al. 2002), cold water from the Omani and Somali upwelling regions is advected eastward toward the interior basin. This contributes to a $-0.85^{\circ} \mathrm{C}$ cooling integrated during summer months. This is lower than what is found by MB99 in their Fig. 7a for horizontal advection in a central AS basin (equivalent to about $-1.2^{\circ} \mathrm{C}$ cooling over the summer). As upwelled surface waters are cold, latent heat losses are reduced and can even reach zero near the coast. This results in a high atmospheric heating rate in upwelling areas, which partly balances subsurface cooling (Fig. 4a). Lateral processes also play a role in heating the mixed layer during the summer monsoon (Fig. 4a). The latter are dominated by Gent and McWilliams (1990) eddy-induced advection localized in the dynamically unstable upwelling areas of Oman and So- 
malia (not shown). One can also note that, despite that the MLD approaches 50-m depth on average over the western AS in summer, $T_{\mathrm{ml}}$ is quite different from T50. This is due to upwelling areas where the thermocline $\left(20^{\circ} \mathrm{C}\right.$ isotherm) can reach shallow depths of $40 \mathrm{~m}$ with a very rapid decrease of temperature underneath the mixed layer.

During the fall intermonsoon (September-October), the mixed layer shoals and warms up due to reduced winds and latent heat losses. It is however counterbalanced by subsurface vertical processes cooling in the upwelling regions. Upwelling has indeed weakened but the stratification at the base of the mixed layer is still well marked, with a sharp and shallow thermocline in such areas. This results in a still significant cooling due to vertical mixing in those areas.

In winter (November-February) the cooling of SST in the western AS is driven by atmospheric forcing, which contributes to a $-2.3^{\circ} \mathrm{C}$ cooling. The heat losses are due to two combined factors. The sustained winds of the northeast monsoon are cold and dry, leading to strong evaporative cooling. This is combined with reduced insolation in winter, especially in the northern part of the basin. The mild sustained wind induces a mixed layer deepening, mostly through a negative buoyancy flux at the air-sea interface (Lee et al. 2000). Rochford et al. (2000) noted a heating contribution from the northward horizontal advection of warm water in the south of the western AS. Our estimation in this area is in acceptable agreement with theirs but it is rather weak compared to the atmospheric forcing on the basin scale $\left(0.6^{\circ} \mathrm{C}\right.$ warming over the season).

\section{3) Eastern Arabian Sea}

As in the western part of the AS, two warming phases occur during intermonsoon phases, and two cooling phases occur during both monsoons. However, oceanic processes are very weak and the SST tendency is mainly driven by atmospheric forcing throughout the year (Fig. 3b, middle panel).

In spring, a strong atmospheric heating occurs and vertical mixing is cooling the basin as in the western AS but to a smaller extent. At the end of spring, a continuous stratification has formed in the upper $50 \mathrm{~m}$ (from about $28.5^{\circ} \mathrm{C}$ at $50 \mathrm{~m}$ to nearly $30^{\circ} \mathrm{C}$ at the sea surface) due to weak winds and strong penetrative solar heating (Sengupta et al. 2002). In summer, the net heat flux becomes markedly negative while it remains near zero in the west. Latent heat flux is stronger because the eastern AS stays warmer, above $28^{\circ} \mathrm{C}$ until mid-August, which allows deep convection to occur. The latent heat flux is the main contributor to cooling during summer, while horizontal advection of cold water from the west

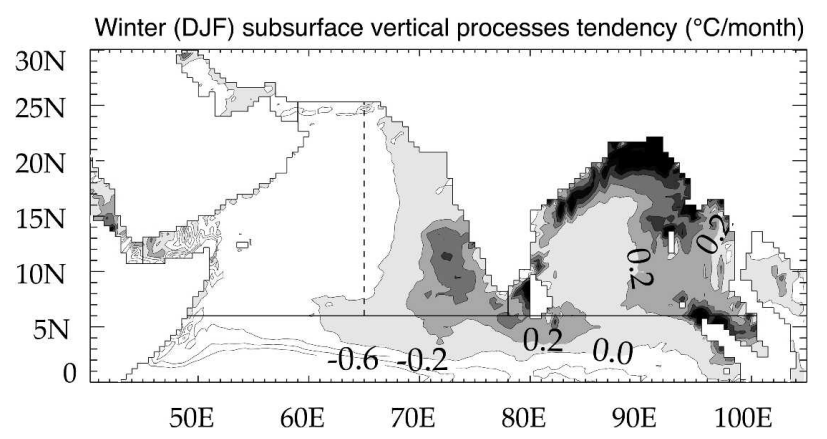

FIG. 5. Map of climatological heating tendency rate computed over 1993-2000 for subsurface vertical processes in winter (DJF). Contours are indicated from -0.6 to $0.6^{\circ} \mathrm{C}$ month $^{-1}$ with contour interval $0.2^{\circ} \mathrm{C} \mathrm{month}^{-1}$. Positive values, indicating warming by the subsurface, are shaded with a grayscale every $0.2^{\circ} \mathrm{C}$ month ${ }^{-1}$.

remains very weak $\left(\simeq-0.1^{\circ} \mathrm{C}\right.$ cooling $)$. The cooling contribution to subsurface vertical processes is also much smaller than in the west (only about $0.6^{\circ} \mathrm{C}$ cooling) because the subsurface water may have been heated in the previous season by the penetrative insolation. As noted by Shetye (1986), a part of this accumulated heat may also be transported vertically through downwelling to deeper layers. The absence of cooling oceanic processes in this basin in summer contributes to maintaining a high SST during that period.

The fall intermonsoon phased in the east is analogous to what happens in the west, except that nearly no oceanic processes act to counterbalance the atmospheric heating. Winter heat fluxes act to cool down the SST and deepen the mixed layer through a negative buoyancy flux at the air-sea interface, as in the western AS. Meanwhile, a barrier layer has developed in the eastern AS (Durand et al. 2007), as seen in Fig. $3 b$ (top panel). The heat accumulated in the barrier layer contributes to warming the deepening mixed layer through subsurface vertical processes during winter (Fig. 5). On the basin scale it represents a total of $0.4^{\circ} \mathrm{C}$ heating throughout winter. This heating by subsurface vertical processes can explain the higher winter SST in the eastern AS than in the west (Table 2).

\section{4) BAy of Bengal}

In the BoB, SST evolution is rather weak during summer and fall, while in winter and spring SST changes are comparable to those in the AS (Fig. 3c).

In spring, net heat flux warms the surface layer as in the Arabian Sea. The resulting temperature stratification at the surface leads to the decay of the previously formed barrier layer. A contribution from subsurface cooling occurs, as in Arabian Sea. Penetrative solar radiation also reaches its maximum $\left(\simeq 45 \mathrm{~W} \mathrm{~m}^{-2}\right)$ and 
heats the subsurface water, creating a continuous vertical stratification in the upper $50 \mathrm{~m}$.

In summer, the $\mathrm{BoB}$ experiences less heat loss due to lower atmospheric forcing than in the eastern AS. Solar heat flux is smaller because of high cloud cover (about $80 \%$ in August) but latent heat flux is also weaker due to lower winds over the bay. The tendency of subsurface vertical processes is negative on the basin scale due to weak upwelling along the east coast of India (Shetye et al. 1991; Shenoi et al. 2002), as well as due to the Sri Lanka cold dome (Vinayachandran and Yamagata 1998). The contribution of the vertical processes is, however, only a $-1.0^{\circ} \mathrm{C}$ cooling from May to August, negligible compared to that of the western AS. This differs from the results of SSS02 or MB99. SSS02 found an important contribution by the vertical processes (diffusion of heat through the bottom) in the BoB. However, this may be due to the fact that they computed this term for a 50-m depth layer whereas the MLD in the $\mathrm{BoB}$ is always less than $35 \mathrm{~m}$ with a growing barrier layer beneath it. Another reason for the difference may be because SSS02 used a constant vertical diffusion coefficient. MB99 also pointed out marked entrainment cooling in the BoB in June and July. They noticed that it should be viewed with caution since they do not include some river discharges, which can be responsible for barrier layer formation and surface warming.

In fall, SST hardly warms. The solar heat flux is weak compared to that in the eastern AS due to high cloud cover over the bay. The barrier layer continues to build while freshwater from precipitation and runoff is advected into the bay along the east coast of India. It reaches a maximum value of $\sim 20 \mathrm{~m}$ on average in winter. During winter, relatively high cloud cover combined with northeasterly cold dry winds result in a strong heat loss due to surface fluxes over the bay $\left(-4.9^{\circ} \mathrm{C}\right.$ cooling in winter). The mixed layer deepens to its maximum, entraining warm subsurface water from the barrier layer (Fig. 5). This water has been heated in the preceding spring season by deep penetrative solar heating. This mechanism could establish a potential link between the winter SST and SST in the previous spring season. The quasi-biennial variability of the summer monsoon seems to be influenced by the Indian Ocean SST in the previous winter and spring seasons (Li et al. 2001), so penetrative solar heat flux may play a role in such a variability. The contribution of subsurface warming reaches $2.1^{\circ} \mathrm{C}$ over the winter season (Table 2). This is a key process that inhibits the bay from losing heat during the winter and keeps its winter SST higher than in the western AS despite strong atmospheric cooling.

Results of the seasonal mixed layer heat budget are qualitatively in agreement with previous studies, especially the one by SSS02, although there are quantitative differences due to the fact that $\mathrm{SSSO} 2$ compute their budget for a fixed 50-m layer. The mixed layer salinity budget was also investigated in the three basins and is consistent with previous studies (e.g., Rao and Sivakumar 2003). Horizontal advection play a dominant role in freshening the western AS evaporation basin during both monsoons and also in driving the variability of SSS in the eastern AS (not shown). Additionally, some new important results have been found. First, the separation between the eastern AS and western AS shows that they are strikingly different. The eastern AS basin can be considered as a transition region between western $\mathrm{AS}$ and $\mathrm{BoB}$. The eastern AS experiences strong summer monsoon winds as in the western AS but no oceanic processes act to cool the SST in summer. It also experiences high summer precipitation as well as the salinity effect, which maintains a high winter SST, as in the BoB. Second, penetration of solar heat flux is a key feature of the forcing. It causes an average of $28 \mathrm{~W} \mathrm{~m}^{-2}$ to be lost beneath the mixed layer over the year, turning the atmospheric contribution of the eastern AS and BoB to a negative one (in our case). Furthermore, it tends to reduce the amplitude of the warm phase of the SST seasonal cycle in the AS because seasons of strongest positive flux coincide with the thinnest mixed layer. Another striking result is the important role of salinity in the seasonal heat budget of the NIO. Salinity effects can explain why winter cooling is greater in the western than in the eastern AS (Table 2). Heat accumulated in the barrier layer in the eastern AS warms the mixed layer in winter by $0.4^{\circ} \mathrm{C}$, while the western AS experiences a subsurface heat loss of $-0.8^{\circ} \mathrm{C}$. SSS02 showed why the BoB remains warmer than the AS during summer. Salinity effects contribute to the enhancement of that SST difference in winter. The $\mathrm{BoB}$ experiences a high barrier layer warming of $2.1^{\circ} \mathrm{C}$ in winter (Table 2), which counterbalances the great atmospheric cooling $\left(-4.9^{\circ} \mathrm{C}\right)$ and enables the bay's winter temperature to stay above $27^{\circ} \mathrm{C}$.

\section{Interannual variability of SST}

At interannual time scales subsurface variability is not well sampled by observations. Models offer a good alternative for investigating the regulating mechanisms of SST in the NIO at those time scales. Furthermore, the good agreement between the results of the previous section and other studies (e.g., SSS02; Rao and Sivakumar 2003) gives some confidence in the model. In this section, after an overview of the interannual variability during the 1993-2000 period, we will investigate the 

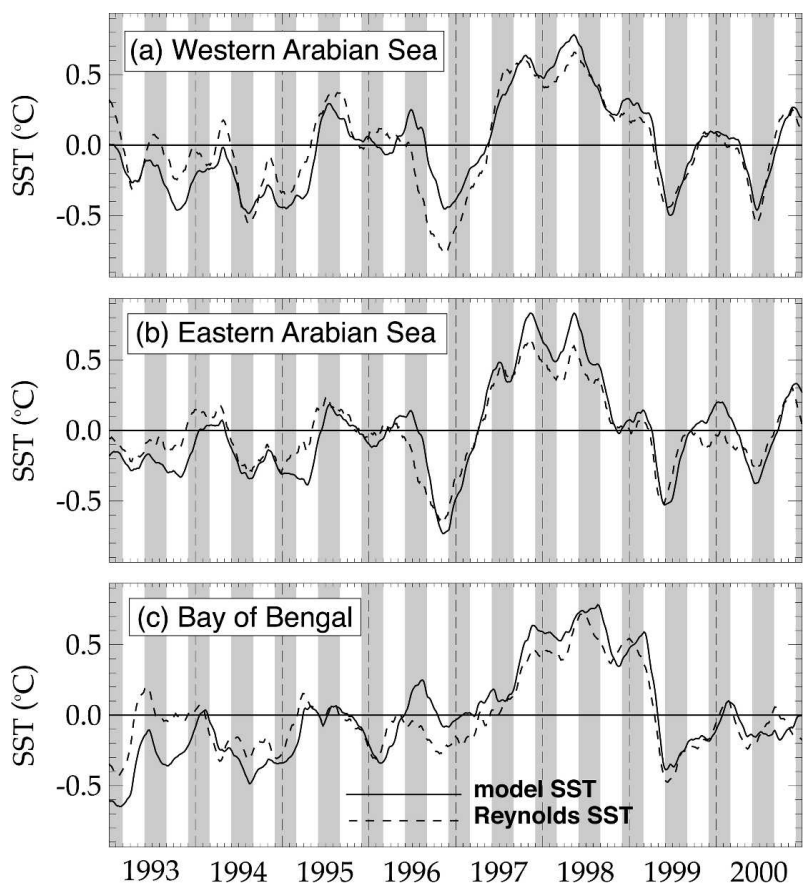

FIG. 6. SST interannual anomaly with respect to the 1993-2000 seasonal cycle in the (a) western AS, (b) eastern AS, and (c) BoB. Data are filtered with a 90-day running mean filter to remove any subseasonal high frequency variability. DJF and JJA periods have been shaded to indicate the winter and summer monsoons.

model heat budget in more detail for our three regions of interest.

\section{a. Overview of the 1993-2000 period}

Figure 6 shows the interannual SST anomaly in the three regions after filtering the intraseasonal variability. Note that there is also strong intraseasonal variabily of the SST and heat budgets at the basin scale, as noted in previous studies (e.g., Vecchi and Harrison 2002), but we will not investigate that here. The main climate anomalies reported elsewhere in the literature on the Indian Ocean for this period are the 1994 Indian Ocean dipole (IOD) (Behera et al. 1999), a longer than usual monsoon in 1996 (Halpert and Bell 1997), and the impacts of the 1997-98 El Niño and the 1997 IOD (Webster et al. 1999).

IOD events generally induce weak positive anomalies in the AS between July and October (Saji et al. 1999). Despite this, the 1994 event is associated with cool anomalies peaking in the middle of the year. These anomalies are rather weak, however (less than $0.5^{\circ} \mathrm{C}$ ), and not especially remarkable when compared, for example, to the cold anomaly in 1999.

The end of 1996 is marked by a clear cooling in the AS (with cold anomalies up to $0.7^{\circ} \mathrm{C}$ ). Vinayachandran
(2004) pointed out that a long summer monsoon can be a decisive parameter for summer cooling in the AS, as it is observed in the Reynolds SST but not as much in the model (Fig. 6). We can also note that enhanced deep convection appeared over the AS during June, with over $10 \%$ increase in NCEP cloud cover over most of the western AS (Lander et al. 1999).

The cold anomaly was then followed by a clear warming of the three subbasins from mid-1997 to early 1999 with anomalies above $0.5^{\circ} \mathrm{C}$ lasting several months. This period was associated with an El Niño in the tropical Pacific, which is known to be associated with basin-scale warming in the Indian Ocean (Yu and Rienecker 2000). The IOD that occurred in 1997 probably also contributed to the persistent warm anomalies in the NIO (Saji et al. 1999). The warm anomalies were followed by cold anomalies that peaked in the middle of 1999 in the three basins. There were no clear anomalies in the BoB in 2000, and the anomalies in the AS were quite similar to those of the previous year, with $\sim 0.5^{\circ} \mathrm{C}$ cold anomalies peaking during the beginning of the summer monsoon.

Figures 7-9 show various quantities averaged over the three subbasins, including the interannual anomalies of the heat budget. Before we go into the details of each subbasin in the following section, we will describe here some features common to the three subbasins. Panel a in all three figures shows the interannual anomalies of the mixed layer depth and of the wind. It is worth noting that the wind strongly controls the mixed layer depth over the three subbasins. Stronger wind will indeed enhance vertical mixing by both creating shear at the mixed layer bottom and enhancing evaporative cooling, thus diminishing the vertical stability of the water column. Panel $\mathrm{c}$ in each of the three figures shows the interannual anomalies of the net and latent heat flux for the three subbasins. The net heat flux interannual variability is dominated by the latent heat flux, with other contributions from solar, longwave, and sensible heat flux playing a negligible role. Two other curves show the latent heat flux recomputed from the Reynolds and Smith (1994) SST rather than the model SST (we explain below the interest of this computation), taking into account or neglecting the airsea humidity gradient interannual anomalies in the computation (but always taking into account wind interannual anomalies). The two curves are very close most of the time over the three subbasins, suggesting that wind interannual variability is the main factor that drives the latent heat flux (and thus the net heat flux) interannual variability. Some local studies in the AS (Konda et al. 2002; Vecchi et al. 2004) suggest that anomalies of air temperature and humidity sometimes 


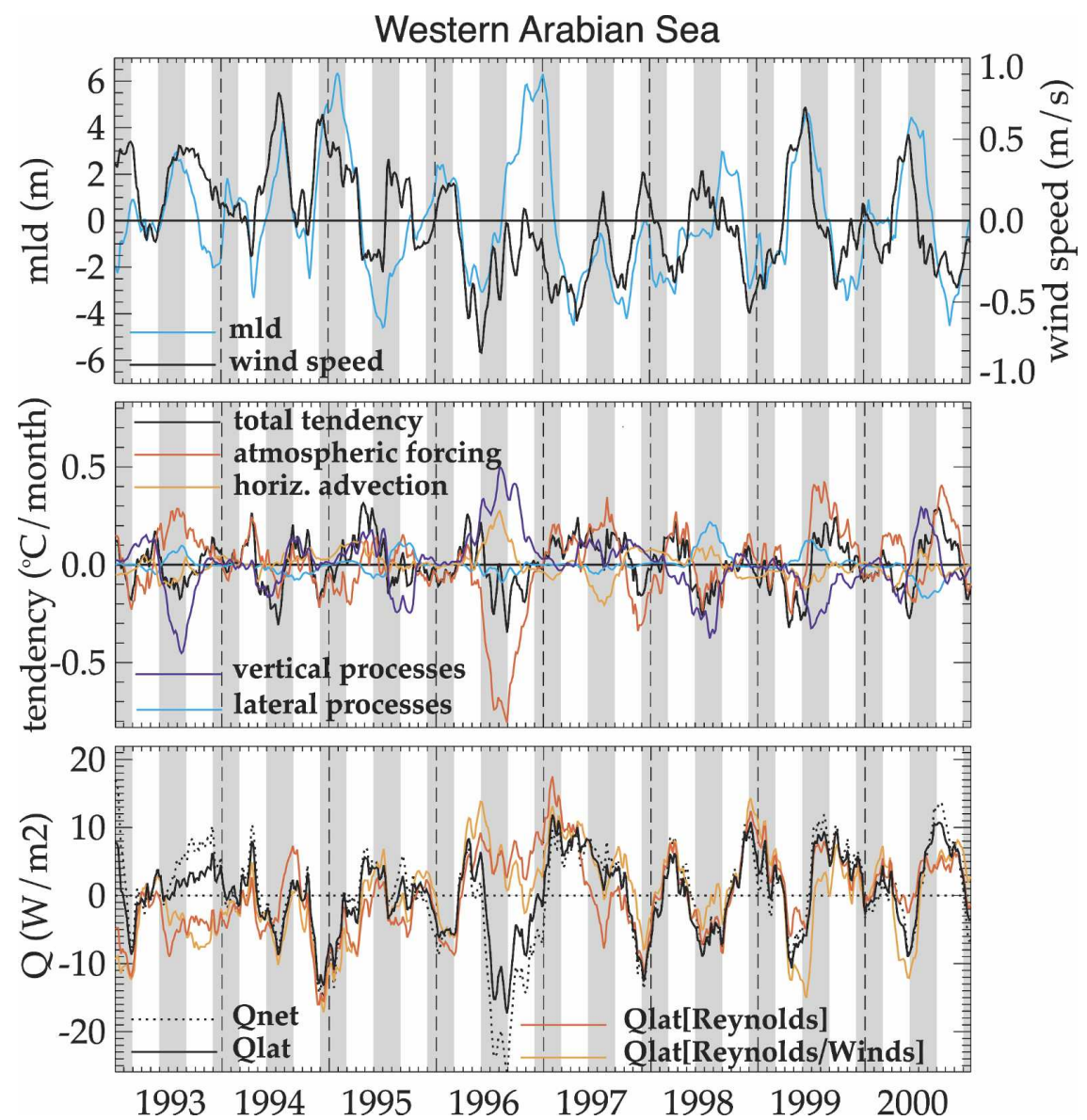

FIG. 7. Interannual anomalies of (top) model MLD and wind speed from ERS data, (middle) SST tendencies, and (bottom) net downward heat flux $\left(Q_{\text {net }}\right)$, downward latent heat flux computed with model SST $\left(Q_{\text {lat }}\right)$, downward latent heat flux computed with Reynolds SST $\left(Q_{\text {lat }}\right.$ [Reynolds]), downward latent heat flux computed with Reynolds SST, and climatological value of the air-sea humidity gradient $\left(Q_{\text {lat }}\right.$ [Reynolds/winds]) in the western AS. Anomalies are computed with respect to the 1993-2000 seasonal cycle. Data are filtered with a 90-day running mean filter to remove any subseasonal high frequency variability. DJF and JJA periods have been shaded to indicate the winter and summer monsoons.

can play a significant role in the latent heat flux, and this is, indeed, the case (e.g., in the western AS in late spring 2000). But overall, at the basin scale, the latent heat flux anomalies are mainly driven by wind speed anomalies, as usually the case in tropical regions (Cayan 1992).

Figure 6 shows that the model reproduces fairly well the SST variability over the three subbasins, with some significant departures from observations. For example, in 1996 the model underestimates the cold anomaly in the western AS and also has a warm bias in the BoB. Since the heat fluxes are computed with the "bulk formulae" using the model SST, this will affect the surface fluxes. To validate the surface fluxes computed by the model, we have also recomputed the surface fluxes using the Reynolds and Smith (1994) SST. This provide some validation of the model interannual flux anomalies. In most instances, since the model SST is close to the observations, the fluxes computed from the model are consistent with those from the observations. But in some cases, as in 1996, there can be important differences: the model latent heat flux anomaly is negative, while the one computed from observations is positive (Fig. 7). In 1996, the model is warmer than observations and thus warmer than the prescribed air temperature (which is always close to the SST). This difference grows to large values, creating an unrealistic SST-air temperature gradient. This gradient becomes strong enough to exert a stronger control over the latent heat flux anomaly than the wind. The difference between the model latent heat flux and the one computed from the Reynolds SST can be compared to the relaxation 


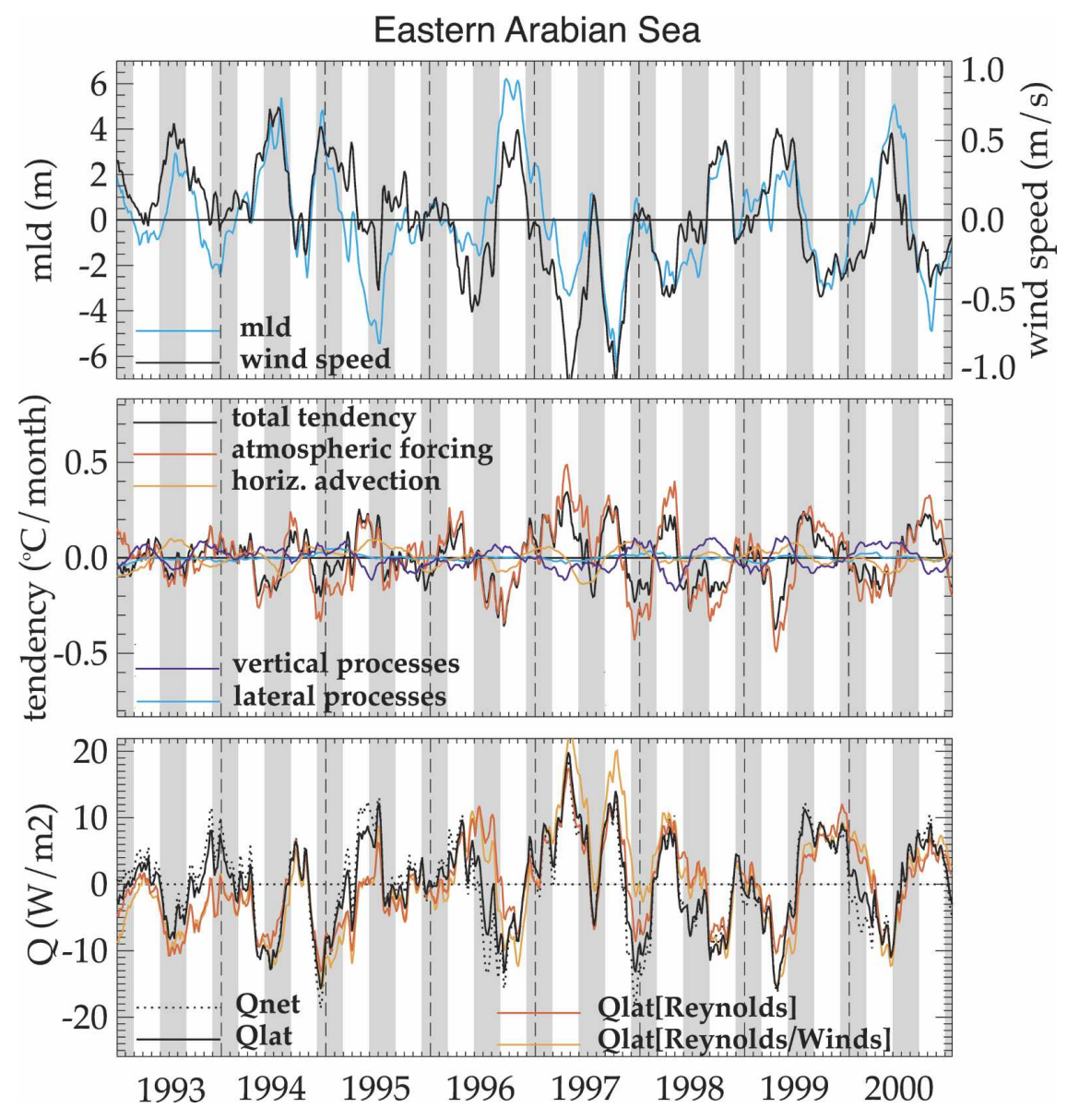

FIG. 8. As in Fig. 7 but for the eastern Arabian Sea.

term used in many other ocean modeling studies. When this terms becomes large, it simply means that missing processes in the model simulation (e.g., in our case, the absence of interannual variability of the clouds and relative humidity or deficiencies in the simulated upwelling) are compensated for by a flux anomaly. In the following subsections, we will thus remain careful in attributing the SST variability to a specific process during periods when this "hidden relaxation term" is strong.

\section{b. Western Arabian Sea}

Figure 7 (middle panel) shows the various terms of the heat budget for the western AS. Atmospheric forcing and vertical processes contribute significantly and alternatively drive the total tendency. Vertical subsurface processes can contribute as a negative feedback to the total tendency (e.g., during the 1996 cooling, or in 1999), but can drive the total tendency on occasion (1993, 1995, 1998). Horizontal advection is weaker than vertical processes, but cannot be neglected; it generally acts as a negative feedback to the atmospheric forcing (e.g., advection warms during the 1996 cooling and cools during the 1997 warming). Lateral processes are dominated by the Gent and McWilliams (1990) advection and is negatively correlated with subsurface vertical processes since its effect is to counteract the enhancement of frontal areas in regions of upwelling. The atmospheric forcing tendency depends both on the net heat flux interannual variations and on the depth of the mixed layer [Eq. (1)]. It can be seen in Fig. 7 that the interannual variations of this term are largely driven by the latent heat flux. However, when comparing the 1998/99 winter (season of high MLD conditions) and 1999 fall (season of low MLD conditions), we see that mixed layer depth seasonal variability modulates this term at second order.

As noted previously, the 1996 cooling phase may correspond to the effect of a hidden relaxation term acting to compensate for missing cooling processes in our model, such as the influence of an increase in cloud cover (a climatological cloud cover is used). The model 


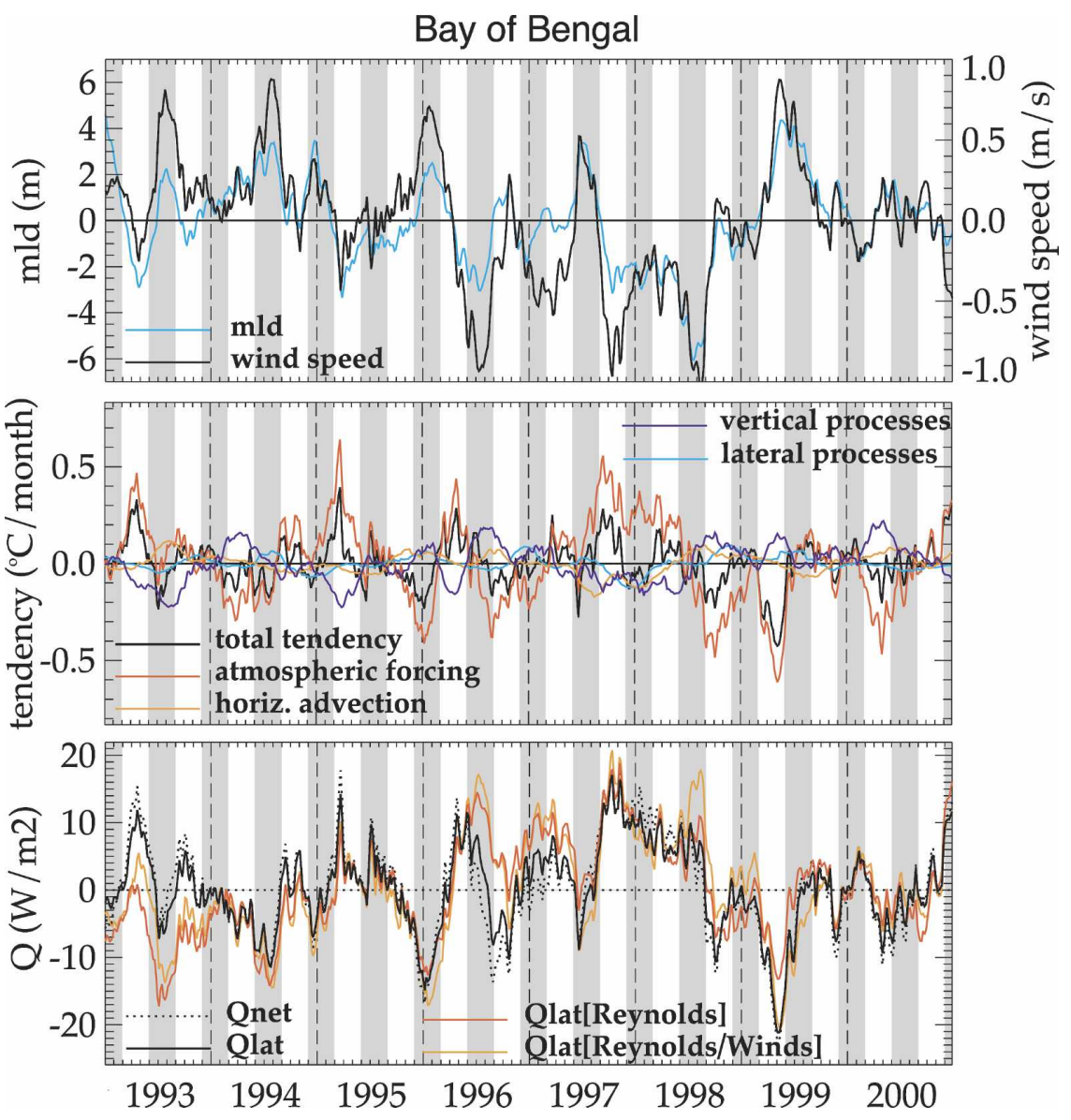

FIG. 9. As in Fig. 7 but for the Bay of Bengal.

seems to fail in reproducing the cooling effect of a longer than usual summer monsoon. During that cooling phase, the vertical mixing tendency anomaly is positive, consistent with a weaker upwelling due to weaker winds. Horizontal advection is usually associated with an influx of cold water through the sloping mixed layer around the upwelling region. The weaker upwelling also leads to a positive tendency anomaly of the horizontal advection.

The following warming period, from December 1996 to May 1998 is characterized by generally negative anomalies of the winds, except in December 1997. During this period latent heat flux is driven by these winds anomalies, which lead to the warming phase. Vertical processes are again well correlated with wind (reduced wind in 1997 leads to reduced cooling by vertical processes). Horizontal advection is here associated with a significant cooling during summer, which resists the general warming tendency.

In summer 1998, a cooling phase begins and continues until the next summer monsoon. The 1998 summer monsoon experiences positive wind anomaly and there- fore an increased heat loss from atmospheric forcing and vertical processes. Because of strong horizontal gradients of temperature around the enhanced upwelling, lateral processes warm the mixed layer at a higher rate than usual. The intense cooling then resumes in spring 1999, largely driven by strong winds and increased evaporative cooling.

The end of 1999 is a good example of a summer monsoon for which atmospheric forcing and vertical processes are acting against each other, as in 1996. The reasons are mainly the same. As SST has been considerably cooled during the premonsoon, the latent heat flux anomaly in summer is partly driven by humidity at the sea surface, which is anomalously low (because of a low temperature) and results in a positive anomaly of the flux tendency. Subsurface processes and horizontal advection are enhanced due to rather stronger winds. As in MB99, we find that vertical oceanic processes have an important contribution to SST anomalies in the western AS. Additionally, the mixed layer heat budget shows that regulation of the SST interannual anomaly in that area appears to be quite complicated, without 
any simple relation between the different tendency terms and the total tendency of SST.

\section{c. Eastern Arabian Sea}

In the eastern AS, the interannual temperature anomaly is primarily driven by atmospheric forcing (Fig. 8). MB99 found that variability in the SST interannual anomaly in the AS or BoB depends on both surface heat fluxes and wind forcing. Here, it is shown that vertical mixing actually plays a secondary role and generally contributes as a weak negative feedback. Oceanic processes thus play a lesser role than in the west where more marked dynamical structures exist.

The wind variability exerts a strong control in this basin and may explain a large part of the SST interannual variability. Net heat flux anomalies are almost entirely driven by latent heat flux anomalies (Fig. 8, bottom panel). These latent heat flux anomalies are themselves well correlated with the wind anomalies (Fig. 8, top and bottom panels). Strong winds (as, e.g., in late 1996) lead to stronger evaporative cooling and to a negative tendency of the forcing term. The wind also exerts strong control over the mixed layer (Fig. 8, top panel) with the strong wind deepening the mixed layer. For thin mixed layer conditions, as in pre- and postmonsoon seasons, the effects of layer variations are predominant in the variations of the vertical term [see Eq. (1)]. A deeper mixed layer (and enhanced mixed layer heat capacity) leads to weaker cooling (i.e., a positive interannual anomaly, e.g., in fall 1998). This explains the weak negative feedback due to vertical processes.

However, in winter 1997/98, the strong evaporative cooling is not driven by the wind (which is near normal) but rather by the higher than usual SST leading to increased latent heat flux. Additionally, the interannual anomalies of the vertical processes are not always due to mixed layer heat capacity variations. In winter 1997/ 98 the positive anomaly of vertical processes is linked to a positive anomaly of the barrier layer thickness, which may be the source of heat for the mixed layer at that time.

\section{d. Bay of Bengal}

In the $\mathrm{BoB}$, the total tendency anomaly is mainly driven by atmospheric forcing (Fig. 9). As in the eastern AS, vertical mixing acts as a negative feedback. The wind is the essential driving factor of the interannual variability in the $\mathrm{BoB}$. The latent heat flux interannual anomalies (which dominate the net heat flux anomalies) are largely driven by wind variability (even if other factors sometimes play a role). The resulting net heat flux variations drive the SST warming or cooling over most of the basin. Other terms can sometimes play a significant role (and even reverse the tendency, as in early 1998), but the only one having a systematic phase relation with forcing is the vertical processes. The negative feedback from the vertical processes is more difficult to explain here than in the eastern AS because of the sign reversal of the vertical processes during the seasonal cycle (vertical processes warm the surface in October-January because of the barrier layer). However, it seems that interannual barrier layer variations do have an impact on the vertical processes, with thicker barrier layers leading to a positive anomaly.

\section{Summary and discussion}

In this paper, a global OGCM simulation of the 1993-2000 period is used to study the mixed layer heat budget of the NIO. Validation of the model mixed layer depth, sea surface temperature, sea level, and surface currents shows a qualitative agreement between the model and available observations. The NIO can be separated into three subbasins. In the BoB and eastern AS (with a meridional separation at $65^{\circ} \mathrm{E}$ ), the SST seasonal cycle is very similar and is essentially driven by atmospheric heat fluxes, with oceanic processes playing a secondary role. In the western AS, surface forcing is still the dominant process but with a large contribution from oceanic processes, especially during the summer monsoon (vertical processes in the upwelling region and horizontal advection through the sloping mixed layer). In the three subbasins, however, the wind is a primary factor in driving the SST seasonal cycle. The net heat flux seasonal cycle is indeed largely controlled by latent heat flux variations since the solar flux effect is damped by the effects of light transmission (incoming solar heat flux is weaker during the monsoon because of clouds, but the deeper mixed layer absorbs a larger fraction of the incoming flux). The transmitted solar heat flux indeed represents an average of $28 \mathrm{~W} \mathrm{~m}^{-2}$ heat loss beneath the mixed layer over the year, with a part of it that might be advected to deeper layers. This can turn the atmospheric contribution of the eastern $\mathrm{AS}$ and the $\mathrm{BoB}$ into a negative one. The latent heat flux seasonal cycle is largely tied to the winds. In the AS, the effect of oceanic processes is also strongly tied to the wind with the largest cooling by the upwelling during the monsoon when the Findlater jet is strongest. The absence of upwelling is the primary cause for higher SST in the BoB and eastern AS than in the western AS during summer. During winter, the salinity stratification plays a clear role in maintaining a high SST in the BoB and eastern AS. The presence of fresh- 
water near the surface allows for heat storage below the surface that can later be recovered by entrainment during winter (with a winter contribution of $0.4^{\circ} \mathrm{C}$ in the eastern $\mathrm{AS}$ and $2.1^{\circ} \mathrm{C}$ in the BoB).

At interannual time scale, the eastern AS and BoB are strongly controlled by the winds through the latent heat flux anomalies, which dominate the net heat flux anomalies. In the western AS, the interannual heat budget is dominated by processes associated with upwelling regions, and most terms in the SST equation do contribute (with the heat forcing and vertical processes being the main ones). The control of the interannual anomalies of SST by the wind is more difficult to establish in this region.

Two potential problems of the model have been identified during this work. First, the model exhibits a 15-m deep MLD bias in regions of negative Ekman pumping during the winter monsoon in the western AS (Fig. 3a, top panel). Second, the net heat flux that we use in the model appears to be too small compared to recent climatologies such as the Southampton Oceanographic Center (SOC) climatology. It is however in reasonable agreement with NCEP-NCAR or ECMWF net heat flux in the region. We should note that accurate estimation of heat flux forcings in the tropical Indian Ocean is an important issue. Further studies are needed if one wants to perform detailed investigations of SST variability in the region (e.g., MB99; Schott and McCreary 2001).

In the NIO the interannual variability of SST is weak but can have important climatic impacts as it occurs around a high SST of $\sim 28^{\circ} \mathrm{C}$. Our analyses suggest that wind variability plays a strong role in driving the eastern AS and BoB through its impact on latent heat fluxes. It must be reminded, though, that our model does not include interannual variability of cloud cover and surface air humidity. In the western AS, the mechanisms that drive that variability cannot be reduced to the winds (e.g., in 1996). Air temperature and relative humidity may also play a role in the interannual variability. When SST is lower than air temperature (as in upwelling areas), variations in relative air humidity can result in high variations in latent heat flux, and relative air humidity might become an important parameter. Interannual cloud cover could also be a solution to improving the model interannual simulation, which shows some limits in the present configuration. MB99 identified a significant contribution from cloud cover and solar radiation in SST anomalies in the northern Indian Ocean. However, sensitivity experiments have been performed with our model on a $2^{\circ} \times 2^{\circ}$ horizontal resolution grid that showed a weak impact by cloud cover and air humidity on interannual variability (differences are about $0.1{ }^{\circ} \mathrm{C}$ or less on the basin scale between the two experiments; not shown). In-depth work on careful specification of the surface boundary layer conditions is thus needed to better evaluate the impact of various atmospheric factors on the upper-layer heat budget. A coupled model with a correct SST variability could also be a solution to further understand the processes that regulate SST in the northern Indian Ocean.

The penetrative solar heating has been shown to be important. Even if we do not know the part of it that is stored in the deeper ocean, it can participate in the transfer of heat to deeper layers, as suggested by Shetye (1986). In this study, we have a high penetrative solar heat flux due to the thin mixed layer in the NIO. This may partly explain how the NIO manages to regulate its SST by warming the layer beneath the surface. This warming is, indeed, around $26 \mathrm{~W} \mathrm{~m}^{-2}$ on annual average in the NIO. In the $\mathrm{BoB}$, it results in a negative heat loss of about $10 \mathrm{~W} \mathrm{~m}^{-2}$, which is partly counterbalanced by vertical process warming in winter. However, the absorbed solar radiation depends on water turbidity, especially on the chlorophyll concentration. In the AS, the effects of biological activity on SST have been shown in several studies (Sathyendranath et al. 1991; Nakamoto et al. 2000). Further experiments including some biooptical parameterizations may be useful for assessing the role of penetrative solar heat flux on SST regulation and the suitability of Jerlov Type I water in the NIO. For example, it could give some biological explanation about the 1996 cooling phase. The latter occurs in the late summer monsoon phase when biological activity has been shown to have the most important impact on SST (Sathyendranath et al. 1991).

When plotting raw time series of our interannual diagnostics, significant variability is found on intraseasonal time scales. This effect is taken into account, but we did not investigate it. Its potential impact on seasonal and interannual variability through scale interactions has been shown in previous studies (e.g., Goswami and Ajaya Mohan 2001) and could also be examined with our model in a future work.

Acknowledgments. The authors thank the ESOPA team for their work in developing and maintaining the ocean model. All computations were performed on the NEC SX-5 of the Institut du Développement et des Ressources en Informatique Scientifique (IDRIS), Orsay, France. We thank P. Terray for fruitful discussions about this work. The authors are thankful to Fabiano Busdraghi for his valuable participation with adding the last Argo floats in the mixed layer depth database. We also thank the two anonymous reviewers for their constructive comments in the revision of the 
manuscript. Sebastien Masson provided the SAXO plotting environment based on IDL. This work is supported by a DGA grant (DGA-CNRS 2001-292) and by funding from the Programme National d'Etude de la Dynamique et du Climat (PNEDC). SSCS and DS thank the Departments of Science and Technology and Ocean Development, government of India, for financial support. The Institut de Recherche pour le Développement (IRD) provided funding for a 3-month visit to the National Institute of Oceanography (NIO), Goa, India, where this work was initiated under the IndoFrench Program of Research in Weather and Climate (IFPREWAC).

\section{REFERENCES}

Anderson, S. P., R. A. Weller, and R. B. Lukas, 1996: Surface buoyancy forcing and the mixed layer of the western Pacific warm pool: Observations and 1D model results. J. Climate, 9, 3056-3085.

Behera, S. K., S. Krishnan, and T. Yamagata, 1999: Unusual ocean-atmosphere conditions in the tropical Indian Ocean during 1994. Geophys. Res. Lett., 26, 3001-3004.

Berliand, M. E., and T. G. Strokina, 1980: Global Distribution of the Total Amount of Clouds. Hydrometeorological Publishing House, $71 \mathrm{pp}$.

Blanke, B., and P. Delecluse, 1993: Variability of the tropical Atlantic Ocean simulated by a general circulation model with two different mixed-layer physics. J. Phys. Oceanogr., 23, $1363-1388$.

Cayan, D. R., 1992: Variability of latent and sensible heat fluxes estimated using bulk formulae. Atmos.-Ocean, 30, 1-42.

Chen, D., A. J. Busalacchi, and L. M. Rothstein, 1994: The roles of vertical mixing, solar radiation and wind stress in a model simulation of the sea surface temperature seasonal cycle in the tropical Pacific Ocean. J. Geophys. Res., 99, $20345-$ 20359.

de Boyer Montégut, C., G. Madec, A. S. Fischer, A. Lazar, and D. Iudicone, 2004: Mixed layer depth over the global ocean: An examination of profile data and a profile-based climatology. J. Geophys. Res., 109, C12003, doi:10.1029/2004JC002378.

_ J J. Mignot, A. Lazar, and S. Cravatte, 2007: Control of salinity on the mixed layer depth in the world ocean. Part I: General description. J. Geophys. Res., in press.

Düing, W., and A. Leetmaa, 1980: Arabian Sea cooling: A preliminary heat budget. J. Phys. Oceanogr., 10, 307-312.

Durand, F., S. R. Shetye, J. Vialard, D. Shankar, S. S. C. Shenoi, C. Ethe, and G. Madec, 2004: Impact of temperature inversions on SST evolution in the southeastern Arabian Sea during the pre-summer monsoon season. Geophys. Res. Lett., 31, L01305, doi:10.1029/2003GL018906.

—, D. Shankar, C. de Boyer Montégut, S. S. C. Shenoi, B. Blanke, and G. Madec, 2007: Modeling the barrier-layer formation in the southeastern Arabian Sea. J. Climate, 20, 21092120.

Eigenheer, A., and D. Quadfasel, 2000: Seasonal variability of the Bay of Bengal circulation inferred from TOPEX/Poseidon altimetry. J. Geophys. Res., 105, 3243-3252.

Findlater, J., 1969: A major low level air current over the Indian
Ocean during the northern summer. Quart. J. Roy. Meteor. Soc., 95, 362-380.

Fischer, A. S., 2000: The upper ocean response to the monsoon in the Arabian Sea. Ph.D. thesis, Massachusetts Institute of Technology-Woods Hole Oceanographic Institution, Woods Hole, MA, 222 pp.

- , R. A. Weller, D. L. Rudnick, C. C. Eriksen, C. M. Lee, K. H. Brink, C. A. Fox, and R. R. Leben, 2002: Mesoscale eddies, coastal upwelling, and the upper-ocean heat budget in the Arabian Sea. Deep-Sea Res. II, 49, 2231-2264.

Gent, P. R., and J. C. McWilliams, 1990: Isopycnal mixing in ocean circulation models. J. Phys. Oceanogr., 20, 150-155.

Goswami, B. N., and R. S. Ajaya Mohan, 2001: Intraseasonal oscillations and interannual variability of the Indian summer monsoon. J. Climate, 14, 1180-1198.

Halpert, M. S., and G. D. Bell, 1997: Climate assessment for 1996. Bull. Amer. Meteor. Soc., 78, S1-S49.

Han, W., J. P. McCreary Jr., and K. E. Kohler, 2001: Influence of precipitation minus evaporation and Bay of Bengal rivers on dynamics, thermodynamics, and mixed layer physics in the upper Indian Ocean. J. Geophys. Res., 106, 6895-6916.

Jacket, D. R., and T. J. McDougall, 1995: Minimal adjustment of hydrographic data to achieve static stability. J. Atmos. Oceanic Technol., 12, 381-389.

Jerlov, N. G., 1968: Optical Oceanography. Elsevier, 194 pp.

Kalnay, E., and Coauthors, 1996: The NCEP/NCAR 40-Year Reanalysis Project. Bull. Amer. Meteor. Soc., 77, 437-471.

Konda, M., N. Imasato, and A. Shibata, 2002: Interannual variability of the sea surface temperature in the Indian Ocean in response to the air-sea turbulent heat exchange. Deep-Sea Res. II, 49, 1527-1548.

Lander, M. A., E. J. Trehubenko, and C. P. Guard, 1999: Eastern Hemisphere tropical cyclones of 1996. Mon. Wea. Rev., 127, 1274-1300.

Lee, C. M., B. H. Jones, K. H. Brink, and A. S. Fischer, 2000: The upper-ocean response to monsoonal forcing in the Arabian Sea: Seasonal and spatial variability. Deep-Sea Res. II, 47, 1177-1226.

Levitus, S., 1998: Climatological Atlas of the World Ocean. NOAA Tech. Rep. 13, Rockville, MD.

Lewis, M. R., M.-E. Carr, G. C. Feldman, W. Esaias, and C. McClain, 1990: Influence of penetrating solar radiation on the heat budget of the equatorial Pacific Ocean. Nature, 347, 543-545.

Li, T., Y. Zhang, C.-P. Chang, and B. Wang, 2001: On the relationship between Indian Ocean sea surface temperature and Asian summer monsoon. Geophys. Res. Lett., 28, 2843-2846.

Madec, G., and M. Imbard, 1996: A global ocean mesh to overcome the North Pole singularity. Climate Dyn., 12, 381-388.

_, P. Delecluse, M. Imbard, and C. Levy, 1999: OPA 8.1 ocean general circulation model reference manual. Notes du Pôle de Modélisation, Institut Pierre Simon Laplace, Paris, France, $91 \mathrm{pp}$.

Masson, S., and Coauthors, 2005: Impact of barrier layer on winter-spring variability of the southeastern Arabian Sea. Geophys. Res. Lett., 32, L07703, doi:10.1029/2004GL021980.

McCreary, J. P., and P. K. Kundu, 1989: A numerical investigation of sea surface temperature variability in the Arabian Sea. $J$. Geophys. Res., 94, 16 097-16114.

,-- , and R. L. Molinari, 1993: A numerical investigation of dynamics, thermodynamics and mixed-layer processes in the Indian Ocean. Prog. Oceanogr., 31, 181-244. 
— , K. E. Kohler, R. R. Hood, S. Smith, J. Kindle, A. S. Fischer, and R. A. Weller, 2001: Influences of diurnal and intraseasonal forcing on mixed-layer and biological variability in the central Arabian Sea. J. Geophys. Res., 106, 7139-7156.

Merryfield, W. J., G. Holloway, and A. E. Gargett, 1999: A global ocean model with double diffusive mixing. J. Phys. Oceanogr., 29, 1124-1142.

Mignot, J., C. de Boyer Montégut, A. Lazar, and S. Cravatte, 2007: Control of salinity on the mixed layer depth in the World Ocean. Part II: Tropical areas. J. Geophys. Res., in press.

Molinari, R. L., J. Swallow, and J. F. Festa, 1986: Evolution of the near-surface thermal structure in the western Indian Ocean during FGGE, 1979. J. Mar. Res., 44, 739-762.

Murray, R. J., 1996: Explicit generation of orthogonal grids for ocean models. J. Comput. Phys., 126, 251-273.

Murtugudde, R., and A. J. Busalacchi, 1999: Interannual variability of the dynamics and thermodynamics of the tropical Indian Ocean. J. Climate, 12, 2300-2326.

Nakamoto, S., S. Prasanna Kumar, J. M. Oberhuber, K. Muneyama, and R. Frouin, 2000: Chlorophyll modulation of sea surface temperature in the Arabian Sea in a mixed layer isopycnal general circulation model. Geophys. Res. Lett., 27, 747-750.

Prasad, T. G., 2004: A comparison of mixed-layer dynamics between the Arabian Sea and Bay of Bengal: One-dimensional model results. J. Geophys. Res., 109, C03035, doi:10.1029/ 2003JC002000.

Qiu, B., S. Chen, and P. Hacker, 2004: Synoptic-scale air-sea flux forcing in the western North Pacific: Observations and their impact on SST and the mixed layer. J. Phys. Oceanogr., 34, 2148-2159.

Rao, R. R., and R. Sivakumar, 2000: Seasonal variability of nearsurface thermal structure and heat budget of the mixed layer of the tropical Indian Ocean from a new global ocean temperature climatology. J. Geophys. Res., 105, 995-1015.

$\ldots$, and -2003 : Seasonal variability of sea surface salinity and salt budget of the mixed layer of the north Indian Ocean. J. Geophys. Res., 108, 3009, doi:10.1029/2001JC000907.

— K. V. S. Ramam, D. S. Rao, and M. X. Joseph, 1985: Surface heat budget estimates at selected regions of the north Indian Ocean during Monsoon-77. Mausam, 36, 21-32.

_ , R. L. Molinari, and J. F. Festa, 1989: Evolution of the climatological near-surface thermal structure of the tropical Indian Ocean. 1. Description of mean monthly mixed layer depth, and sea surface temperature, surface current, and surface meteorological fields. J. Geophys. Res., 94, 10 80110815.

Reynolds, R. W., and T. M. Smith, 1994: Improved global sea surface temperature analysis using optimum interpolation. $J$. Climate, 7, 929-948.

Rochford, P. A., J. C. Kindle, P. C. Gallacher, and R. A. Weller, 2000: Sensitivity of the Arabian Sea mixed layer to 1994-1995 operational wind products. J. Geophys. Res., 105, $14141-$ 14162.

Roullet, G., and G. Madec, 2000: Salt conservation, free surface and varying volume: A new formulation for ocean GCMs. $J$. Geophys. Res., 105, 23 927-23 942.

Saji, N. H., B. N. Goswami, P. N. Vinayachandran, and T. Yamagata, 1999: A dipole mode in the tropical Indian Ocean. $\mathrm{Na}$ ture, 401, 360-363.

Sathyendranath, S., A. D. Gouveia, S. R. Shetye, P. Ravindran, and T. Platt, 1991: Biological control of surface temperature in the Arabian Sea. Nature, 349, 54-56.

Schott, F. A., and J. P. McCreary, 2001: The monsoon circulation of the Indian Ocean. Prog. Oceanogr., 51, 1-123.

Sengupta, D., P. K. Ray, and G. S. Bhat, 2002: Spring warming of the eastern Arabian Sea and Bay of Bengal from buoy data. Geophys. Res. Lett., 29, 1734, doi:10.1029/2002GL015340.

Shankar, D., P. N. Vinayachandran, and A. S. Unnikrishnan, 2002: The monsoon currents in the north Indian Ocean. Prog. Oceanogr., 52, 63-120.

_, and Coauthors, 2004: Observational evidence for westward propagation of temperature inversions in the southeastern Arabian Sea. Geophys. Res. Lett., 31, L08305, doi:10.1029/ 2004 GL019652.

Shenoi, S. S. C., D. Shankar, and S. R. Shetye, 2002: Differences in heat budgets of the near-surface Arabian Sea and Bay of Bengal: Implications for the summer monsoon. J. Geophys. Res., 107, 3052, doi:10.1029/2000JC000679.

$[$ _ - , and _ 2004: Remote forcing annihilates barrier layer in southeastern Arabian Sea. Geophys. Res. Lett., 31, L05307, doi:10.1029/2003GL019270.

- - - V. V. Gopalakrishna, and F. Durand, 2005a: Role of ocean in the genesis and annihilation of the core of the warm pool in the southeastern Arabian Sea. Mausam, 56, 147-160.

,$- \ldots$, and S. R. Shetye, 2005b: On the accuracy of the simple ocean data analysis for estimating heat budgets of the nearsurface Arabian Sea and Bay of Bengal. J. Phys. Oceanogr., 35, 395-400.

Shetye, S. R., 1986: A model study of the seasonal cycle of the Arabian Sea surface temperature. J. Mar. Res., 44, 521-542.

- S. S. C. Shenoi, A. D. Gouveia, G. S. Michael, D. Sundar, and G. Nampoothiri, 1991: Wind-driven coastal upwelling along the western boundary of the Bay of Bengal during the southwest monsoon. Cont. Shelf Res., 11, 1397-1408.

Smith, W. H. F., and D. T. Sandwell, 1997: Global sea floor topography from satellite altimetry and ship depth soundings. Science, 277, 1956-1962.

Timmermann, R., H. Goosse, G. Madec, T. Fichefet, C. Ethe, and V. Dulière, 2005: On the representation of high latitude processes in the ORCA-LIM global coupled sea ice-ocean model. Ocean Modell., 8, 175-201.

Trenberth, K. E., J. G. Olson, and W. G. Large, 1989: A global ocean wind stress climatology based on the ECMWF analyses. NCAR/TN-338+STR, National Center for Atmospheric Research, Boulder, CO, 93 pp.

UNESCO, 1996: Monthly and Annual Discharges Recorded at Vaiours Selected Stations, Twenty-Year Catal. Vol. 2, Discharge of Selected Rivers of the World, UNESCO, $600 \mathrm{pp}$.

Vecchi, G. A., and D. E. Harrison, 2002: Monsoon breaks and subseasonal sea surface temperature variability in the Bay of Bengal. J. Climate, 15, 1485-1493.

_ S.-P. Xie, and A. S. Fischer, 2004: Ocean-atmosphere covariability in the western Arabian Sea. J. Climate, 17, 12131224.

Vialard, J., and P. Delecluse, 1998: An OGCM study for the TOGA decade. Part I: Role of salinity in the physics of the western Pacific fresh pool. J. Phys. Oceanogr., 28, 1071-1088.

- C. Menkes, J.-P. Boulanger, P. Delecluse, E. Guilyardi, M. J. McPhaden, and G. Madec, 2001: A model study of oceanic mechanisms affecting equatorial Pacific sea surface temperature during the 1997-98 El Niño. J. Phys. Oceanogr., 31, 1649-1675.

Vinayachandran, P. N., 2004: Summer cooling of the Arabian Sea 
during contrasting monsoons. Geophys. Res. Lett., 31, L13306, doi:10.1029/2004GL019961.

—_, and T. Yamagata, 1998: Monsoon response of the sea around Sri Lanka: Generation of thermal domes and anticyclonic vortices. J. Phys. Oceanogr., 28, 1946-1960.

- V. S. N. Murty, and V. Ramesh Babu, 2002: Observations of barrier layer formation in the Bay of Bengal during summer monsoon. J. Geophys. Res., 107, 8018, doi:10.1029/ 2001JC000831.

Webster, P. J., V. O. Magaña, T. N. Palmer, J. Shukla, R. A. Tomas, M. Yanai, and T. Yasunari, 1998: Monsoons: Processes, predictability, and the prospects for prediction. J. Geophys. Res., 103, 14 451-14 510.

, A. M. Moore, J. P. Loschnigg, and R. R. Leben, 1999:
Coupled ocean-atmosphere dynamics in the Indian Ocean during 1997-98. Nature, 40, 356-360.

Weller, R. A., M. F. Baumgartner, S. A. Josey, A. S. Fischer, and J. C. Kindle, 1998: Atmospheric forcing in the Arabian Sea during 1994-1995: Observations and comparisons with climatology and models. Deep-Sea Res. II, 45, 1961-1999.

Xie, P., and P. A. Arkin, 1996: Analysis of global monthly precipitation using gauge observations, satellite estimates, and numerical model predictions. J. Climate, 9, 840-858.

$\mathrm{Yu}, \mathrm{L}$., and M. M. Rienecker, 2000: Indian Ocean warming of 1997-1998. J. Geophys. Res., 105, 16 923-16939.

Yu, Z., and J. P. McCreary Jr., 2004: Assessing precipitation products in the Indian Ocean using an ocean model. J. Geophys. Res., 109, C05013, doi:10.1029/2003JC002106. 